\title{
Protocolo de experimentação patogenética homeopática em humanos
}

\author{
Protocol of homeopathic pathogenetic trial in humans
}

\author{
Marcus Zulian Teixeira
}

Teixeira MZ. Protocolo de experimentação patogenética homeopática em humanos / Protocol of homeopathic pathogenetic trial in humans. Rev Med (São Paulo). 2013;92(4):242-63.

\begin{abstract}
RESUMO: A experimentação ou ensaio patogenético homeopático $(\mathrm{EPH})$ é o método de investigação clínico-farmacológica utilizado pela homeopatia para conhecer as manifestações patogenéticas (sinais e sintomas) que as substâncias despertam nos seres humanos, possibilitando a aplicação do princípio da similitude terapêutica. Instrumento indispensável na assistência, na pesquisa e no ensino da homeopatia, apresenta modelos de aplicação diversos ao longo destes dois séculos de prática homeopática, através dos quais milhares de substâncias foram experimentadas em indivíduos humanos sadios e tiveram suas manifestações sintomáticas descritas nas Matérias Médicas Homeopáticas. Apesar da sua importância no desenvolvimento da episteme homeopática, a Homeopatia Brasileira carece, na atualidade, de protocolos de pesquisa patogenética condizentes com as exigências da metodologia científica moderna, que tornariam os testes mais confiáveis e facilitariam sua aprovação perante os comitês de ética em pesquisa das instituições que pretendam executá-los. Este protocolo de experimentação patogenética homeopática foi desenhado com o intuito de suprir esta demanda, seguindo os passos e as exigências necessárias à elaboração de um projeto de pesquisa clínica em humanos, a fim de disponibilizar uma sistemática que permita a uniformização do procedimento e sua aplicação nas diversas instâncias que se proponham a realizar pesquisa patogenética homeopática. A possibilidade da publicação deste protocolo numa revista indexada e de livre acesso, permitindo a ampla divulgação de um tema imprescindível ao entendimento e ao progresso da homeopatia, facilita o esclarecimento da racionalidade científica homeopática perante a classe médica e a disseminação da proposta perante o movimento homeopático brasileiro.
\end{abstract}

Descritores: Experimentação medicamentosa/patogenicidade; Sintomas patogenéticos; Patogenesia homeopática; Ensaio clínico fase I; Sintomas clínicos em homeopatia; Fontes da matéria médica.

\begin{abstract}
Homeopathic pathogenetic trial (HPT) or experimentation is the clinical and pharmacological research method used by homeopathy to get to know the pathogenetic manifestations (signs and symptoms) that the substances arouse in humans, enabling the application of the principle of therapeutic similitude. Indispensable tool in care, research and teaching of homeopathy, presents various application models throughout these two centuries of homeopathic practice by which thousands of substances have been tested in healthy human individuals and had their symptomatic manifestations described in the Homeopathic Materia Medica. Despite its importance in the development of homeopathic episteme, the Brazilian Homeopathy lacks, at present, of pathogenetic research protocols consistent with the requirements of modern scientific methodology, which would make the proving more reliable and would facilitate its approval before the research ethics committees of the institutions who wish to run them. This protocol of homeopathic pathogenetic trial was designed in order to meet this demand, following the steps and requirements necessary for the production of a clinical research project on human, in order to make available a systematic that allows the standardization of the procedure and its application in several instances that propose to carry out pathogenetic homeopathic research. The possibility of publication of this protocol on an indexed, open-access journal, allowing wide dissemination of a topic essential to the understanding and progress of homeopathy, facilitates the clarification of scientific rationality to the homeopathic medical class and the dissemination of the proposal before the Brazilian homeopathic movement.
\end{abstract}

KEY WORDS: Experiment of substances/pathogenicity; Pathogenetic symptoms; Pathogenesy, homeopathic; Clinical trial, phase I; Clinical symptoms in homeopathy; Materia medica sources.

Coordenador da disciplina optativa "Fundamentos da Homeopatia" (MCM0773) da Faculdade de Medicina da Universidade de São Paulo (FMUSP).

Endereço para correspondência: Marcus Zulian Teixeira. Hospital das Clínicas da FMUSP. Serviço de Clínica Médica Geral. Av. Dr. Enéas de Carvalho Aguiar, 155, 4ªndar - bloco 6. CEP: 05403-900. São Paulo, SP. E-mail: mzulian@usp.br 


\section{INTRODUÇÃO}

$\mathbf{O}$ modelo homeopático de tratamento das doenças humanas foi criado em 1796 por Samuel Hahnemann a partir da autoexperimentação patogenética da Cinchona officinalis e fundamenta-se nos seguintes pressupostos: aplicação do princípio de cura pela semelhança sintomática, utilizando doses infinitesimais de substâncias medicinais experimentadas previamente em indivíduos sadios, prescritas na forma de medicamentos únicos que englobem a totalidade sintomática característica da individualidade enferma ${ }^{1,2}$.

Contrapondo o tratamento enantiopático (paliativo, antipático ou antagônico) moderno, que utiliza o princípio dos contrários para suprimir os sintomas incomodativos e manter em equilíbrio as disfunções orgânicas, o tratamento homeopático visa estimular uma reação do organismo contra suas próprias mazelas, induzida pela propriedade dos medicamentos de causarem transtornos semelhantes nos indivíduos sadios: "toda droga causa certa alteração no estado de saúde humano pela sua ação primária; $[\ldots]$ a esta ação primária do medicamento, o organismo opõe sua força de conservação, chamada ação secundária ou reação vital, no sentido de neutralizar o distúrbio inicial" (Organon da arte de curar, § 63) $)^{3}$. Como "reação vital" ou "ação secundária", entendamos a resposta integrada do organismo (sistema psico-neuro-imuno-endócrino-metabólico) no sentido de manter a homeostase interna.

Observando que esta ação secundária ou reação vital (resposta homeostática integrada) poderia ser empregada de forma curativa, desde que direcionada no sentido correto, Hahnemann propôs um modelo terapêutico que utiliza medicamentos que produzem sinais e sintomas semelhantes à doença natural, com o intuito de estimular uma reação paradoxal (efeito rebote) $)^{4-7}$ do organismo contra seus próprios distúrbios. Daí surgiu o princípio de cura pela similitude: "todo medicamento capaz de despertar determinados sintomas no indivíduo sadio, pode ser capaz de curar estes mesmos sintomas no indivíduo doente".

Com o objetivo de conhecer os poderes intrínsecos das drogas em promover manifestações patogenéticas nos indivíduos, a fim de poder aplicar o princípio da similitude terapêutica, Hahnemann passou a experimentar uma série de substâncias em indivíduos considerados 'sadios' ("experimentação patogenética homeopática" ou "ensaio patogenético homeopático" ou EPH), observando os efeitos diretos ou primários de qualquer ordem (psíquica, geral e física) despertados pelas substâncias nos experimentadores e confeccionando a Matéria Médica Homeopática ${ }^{8-10}$, livros textos que contêm a descrição de todos os sinais e sintomas que as substâncias causaram nos experimentadores. À medida que defrontava pacientes com manifestações sintomáticas semelhantes às drogas experimentadas, administrava-as a estes enfermos no sentido de despertar uma reação homeostática do organismo no sentido curativo (similia similibus curentur).

Assim sendo, qualquer substância (natural ou sintética) pode se tornar um medicamento homeopático (utilizado segundo o princípio da similitude terapêutica), desde que seja experimentada em seres humanos (em doses ponderais e/ou infinitesimais) e desperte sinais e sintomas nesses indivíduos.

Segundo a experimentação farmacológica moderna, a experimentação patogenética homeopática $(\mathrm{EPH})$ se assemelha aos modernos "ensaios clínicos farmacológicos de fase 1", visando investigar os diversos efeitos patogenéticos (eventos adversos) de substâncias inertes, tóxicas ou medicinais preparadas segundo a farmacotécnica homeopática (dinamizações ou ultradiluições homeopáticas), a fim de serem utilizados posteriormente como referência na terapêutica homeopática.

Além de ser utilizada como modelo de pesquisa clínico-farmacológica homeopática, identificando as características intrínsecas às substâncias que poderão ser empregadas segundo o princípio da similitude terapêutica, a EPH é também aplicada como um método didático e científico para validar os pressupostos homeopáticos. Por fazer parte das "pesquisas envolvendo seres humanos", torna-se imprescindível a elaboração de desenhos experimentais de alta qualidade metodológica, a fim de que correspondam às exigências éticas e científicas das instituições em que se pretendam executá-las e produzam patogenesias cada vez mais elaboradas e confiáveis.

Baseado nas premissas hahnemannianas, em modelos de experimentações patogenéticas atuais e nos ditames da metodologia científica, este Protocolo de Experimentação Patogenética em Humanos ${ }^{11}$ foi delineado com o objetivo de disponibilizar ao meio homeopático um ensaio patogenético homeopático de livre acesso, amplo e completo segundo as exigências da pesquisa clínicofarmacológica moderna, abrangendo os quesitos científicos necessários para que possa ser aplicado eticamente perante as diversas instituições de pesquisa.

\section{EXPERIMENTAÇÃ O PAT OGENÉTICA HOMEOPÁTICA - REVISÃO HISTÓRICA}

Desde a fundamentação do modelo homeopático em 1796, foram realizados diversos protocolos de experimentação patogenética homeopática (EPH), mantendo em sua essência as diretrizes estipuladas por Hahnemann, acrescidas dos avanços da metodologia científica da época.

\section{Experimentação patogenética homeopática (EPH) segundo Hahnemann}

Traçando as diretrizes básicas para a realização de um protocolo de experimentação patogenética homeopática, 
Hahnemann discorre nos parágrafos 105 a 144 do Organon da arte de curar $^{3}$ a forma protocolar como as substâncias "dinamizadas" (método farmacotécnico homeopático em que as substâncias são diluídas e agitadas em série, com suas peculiaridades descritas na Farmacopéia Homeopática Brasileira $^{12}$ ) deveriam ser experimentadas em sua época.

Discorrendo sobre a necessidade de observar, de forma clara e precisa, o efeito dos medicamentos dinamizados em indivíduos sadios, Hahnemann atenta para o fato de que em "pessoas doentes" os sintomas da doença misturar-se-ão aos efeitos primários dos medicamentos, dificultando a clara percepção destes. Enfatiza que a experimentação em "pessoas sadias" é o caminho mais seguro e natural, para se descobrir "os efeitos peculiares dos medicamentos" (Organon da arte de curar, $\S 107,108)^{3}$.

Observando nítida analogia entre os registros de autores antigos, que relatavam os eventos adversos de drogas ingeridas por motivos diversos (intoxicações acidentais, tentativas de suicídio, tratamentos inadequados, etc.), com as suas próprias observações, Hahnemann reforça a validade de sua metodologia experimental de estudo do poder curativo das drogas segundo a dinâmica homeopática, atribuindo a este 'poder patogenético' a categoria de 'lei natural, definida e imutável", ampliando esta propriedade a todas as substâncias da Natureza, naturais ou sintéticas, e a todos os indivíduos sensíveis, sãos ou doentes (Organon da arte de curar, $\S 111)^{3}$.

Descrevendo a forma como as diversas substâncias experimentadas poderiam afetar o organismo humano, despertando seus efeitos patogenéticos nos indivíduos, prioriza a "suscetibilidade individual" como fator imprescindível para que alguns sintomas sejam produzidos com maior frequência, enquanto que outros se manifestariam em poucos indivíduos idiossincrásicos. Define "idiossincrasia" como a capacidade que o indivíduo possui, mediante um determinado estímulo, em manifestar certas características incomuns à maioria das pessoas, ou seja, "a forma peculiar de cada indivíduo reagir frente a um mesmo estímulo" (Organon da arte de curar, § 116$117)^{3}$.

Em conformidade às suas propriedades internas e externas, físicas e químicas, cada substância apresenta a peculiaridade de despertar no organismo humano manifestações patogenéticas particulares, que diferem dos efeitos primários das demais drogas: assim como existe a idiossincrasia individual para captar determinadas características do agente, qualquer agente específico tem sua propriedade intrínseca de afetar as individualidades humanas. Devido a esta forma peculiar de cada substância afetar o organismo humano, seus poderes medicinais devem ser estudados minuciosa e precisamente, segundo "experimentos puros e cuidadosos no organismo sadio", a fim de podermos empregar para cada caso específico o medicamento certo para restabelecer a saúde orgânica (Organon da arte de curar, § 118-120) ${ }^{3}$.
Hahnemann alerta para o fato de que as substâncias experimentadas devem estar na forma "pura, autêntica, simples e natural", a fim de que os resultados desse método experimental possam ser reproduzidos, acrescentando novos efeitos primários patogenéticos em reexperimentações futuras da mesma substância e empregando os efeitos secundários curativos da mesma através da similitude terapêutica (Organon da arte de curar, § 122-124) ${ }^{3}$.

Buscando selecionar o 'experimentador ideal', Hahnemann estabelece normativas em relação aos hábitos e vícios alimentares, uso de substâncias medicinais, ao caráter e ao modo de vida. Frisa a importância da autoobservação e da capacidade de expressar claramente suas sensações e sentimentos, além da necessidade de possuir "um organismo sadio, dentro de seus padrões". Quanto à auto-observação, orienta ao experimentador um exame minucioso das várias modalidades do sintoma manifesto ( situações diversas em que ocorram 'agravações' ou 'melhorias', 'horário de aparecimento', 'lateralidade', etc.). Com estas "modalizações sintomáticas" teremos "particularidades características de cada sintoma", fator imprescindível para a individualização do medicamento (Organon da arte de curar, $\S 125,126$ e 133).

Dentre todas as classes de experimentadores, sugere a escolha do 'médico sadio', sem preconceitos, criterioso e sensível como "experimentador ideal". Referindo-se novamente ao caráter e à moral do experimentador, que fundamentam a prerrogativa dele ser uma "pessoa fidedigna e conscienciosa", reprova a utilização de experimentadores remunerados e pouco confiáveis, que poderão fornecer dados incertos ou falsos (Organon da arte de curar, $\S 141$ e nota do $\S 143)^{3}$.

Orienta que a experimentação dos medicamentos seja repetida em diversos indivíduos sadios de ambos os sexos, para que conheçamos todos os seus efeitos patogenéticos, dizendo que "nem todos os sintomas peculiares de um medicamento se manifestam em uma única pessoa e nem todos ao mesmo tempo ou no mesmo experimento". Por outro lado, um medicamento homeopaticamente escolhido poderia produzir num único indivíduo doente suscetível todas as manifestações que lhe são próprias, curando-as, segundo "uma eterna e imutável lei da natureza, graças à qual o medicamento põe em atividade todos os seus efeitos, em todo e qualquer indivíduo ao qual é administrado para tratar um estado mórbido de distúrbios semelhantes" (Organon da arte de curar, $\S 127,134-136)^{3}$.

Mesmo que características semelhantes já tenham surgido anteriormente nos experimentadores de forma espontânea, "todos os distúrbios, fenômenos e mudanças no estado de saúde dos experimentadores durante o período de ação de um medicamento, derivam, unicamente, deste medicamento e devem ser considerados e registrados como pertencentes especialmente a ele", pois se refere ao "poder inerente da droga despertar sintomas em indivíduos suscetíveis". Por outro lado, 'qualquer sintoma 
despertado pelo medicamento no experimentador é próprio do indivíduo', pois do contrário não encontraria a predisposição para se manifestar no mesmo (Organon da arte de curar, $\S 138)^{3}$.

Abordando a forma sistemática como os sintomas deveriam ser coletados e registrados, Hahnemann estipula que o experimentador "deve anotar claramente suas sensações, distúrbios, fenômenos e alterações no estado de saúde no momento em que eles se produzem", mencionando o dia em que apareceram e o tempo de duração. O médico que dirige a experimentação deve examinar "o relato na presença do experimentador, quando ainda conserva tudo na memória", para investigar os sintomas mais detalhadamente, assumindo grande responsabilidade neste papel (Organon da arte de curar, $\S 139$ e 140) ${ }^{3}$.

Discorrendo sobre a melhor forma (posologia) de se administrar as substâncias medicinais, a fim de que os efeitos patogenéticos sejam despertados em experimentadores sadios, Hahnemann prioriza o poder medicamentoso das substâncias "dinamizadas" em favor das substâncias em "estado bruto", dizendo que através das diluições, potencializadas por trituração e sucussão adequadas, "as forças que permanecem ocultas em seu estado bruto e como que adormecidas desenvolvem-se e sua atividade desperta de maneira incrível". Como posologia padrão, escolhe as doses únicas diárias da potência $30 \mathrm{cH}$ (diluição de $1: 10^{60}$, equivalente à concentração $10^{-60} \mathrm{M}$ ), por vários dias, como forma de administração para se investigar as forças medicamentosas de qualquer substância (Organon da arte de curar, § 128 e 129) . $^{3}$.

A utilização de 'dose única na potência $30 \mathrm{cH}$ 'é útil na observação pura da "ordem de sucessão" e "duração" dos efeitos patogenéticos de uma determinada substância, que podem ser mais bem conhecidos mediante a comparação de diversos experimentos. Nas 'doses repetidas', perdemos a percepção clara destas variáveis qualitativas do medicamento (Organon da arte de curar, $\S 130$ e 131) Priorizando a segurança dos experimentadores, indica este tipo de posologia moderada (poucas doses da substância dinamizada na potência $30 \mathrm{cH}$ ) na experimentação patogenética, alertando para os efeitos danosos das doses repetidas em indivíduos suscetíveis (Organon da arte de curar, $\S 137)^{3}$.

Por outro lado, na captação quantitativa de 'todos os sintomas' de uma substância de poder patogenético desconhecido, Hahnemann sugere o emprego de doses repetidas e crescentes: "Quando se quer, porém, averiguar apenas os sintomas em si, especialmente os de uma substância medicamentosa fraca, sem considerar a ordem de sucessão dos fenômenos e a duração do efeito do medicamento, é preferível, então, dá-las durante diversos dias sucessivos, aumentando-se a dose diariamente. Desse modo, a ação de um medicamento ainda desconhecido, mesmo o mais suave, revelar-se-á, principalmente se experimentado em pessoas sensíveis" (Organon da arte de curar, § 132) .

Finalizando suas orientações protocolares para a realização da experimentação patogenética homeopática, sintetiza a importância do desenvolvimento de desenhos experimentais mais apropriados, permitindo a depuração do método e a confecção de Matérias Médicas Homeopáticas em que "deve-se excluir totalmente tudo o que seja conjectura, mera afirmação ou ficção; tudo deve ser a pura linguagem da natureza, cuidadosa e seriamente interrogada" (Organon da arte de curar, $\S 143$ e 144) $)^{3}$.

Inaugurando uma metodologia experimental farmacológica para a investigação controlada dos poderes patogenéticos das drogas de sua época, que se assemelha aos modernos ensaios clínicos farmacológicos fase 1 (experimentos 'controlados'; pequenas amostras de voluntários sadios; observação de efeitos patogenéticos objetivos e subjetivos; pré-requisito para a utilização terapêutica futura das substâncias; etc.), Hahnemann sistematizou condutas que visassem minimizar os vieses ou erros sistemáticos advindos de sua pesquisa clínicofarmacológica (critérios de inclusão e exclusão dos participantes a fim de que os relatos fossem fidedignos; emprego de substâncias únicas, puras e simples em cada experimentação, permitindo a reprodutibilidade do método; auto-observação, anotações e supervisão minuciosa, segundo premissas pré-estabelecidas, permitindo a descrição detalhada e precisa dos fenômenos; isolamento da interferência de fatores externos nos resultados, secundários à dieta, estilo de vida e consumo de substâncias medicinais; orientação quanto à posologia mais apropriada, etc.), fornecendo um modelo pragmático de raciocínio e conduta que deveria ser seguido e melhorado pelos propagadores do método homeopático de investigação científica.

Ao longo de sua vida, Hahnemann experimentou 67 substâncias e publicou 101 experimentações patogenéticas homeopáticas, agregando aos sintomas despertados nas experimentações em indivíduos sadios os efeitos patogenéticos tóxicos e/ou iatrogênicos despertados pelas mesmas substâncias em indivíduos humanos e citados na literatura ${ }^{8-10}$.

\section{Qualidade metodológica das EPHs contemporâneas}

Diversas EPHs foram realizadas no desenvolvimento da homeopatia pós-Hahnemann, ampliando o conhecimento dos efeitos patogenéticos através da re-experimentação de medicamentos conhecidos e da experimentação de substâncias novas, perfazendo um total de, aproximadamente, 3000 substâncias experimentadas.

Dando continuidade a estudos anteriores ${ }^{13-15}$, Dantas et al. ${ }^{16,17}$ realizaram uma revisão sistemática sobre a qualidade das EPHs contemporâneas, na qual foram analisadas 156 publicações que descreveram 20.538 efeitos patogenéticos de 143 medicamentos testados em 2.815 voluntários no período de 1945-1995. Segundo um 
Índice de Qualidade Metodológica (IQM) desenvolvido pelos autores, com escore mínimo de 4 e máximo de 16 pontos, obtido a partir de 4 componentes (randomização; mascaramento de voluntários e investigadores; critérios de inclusão e exclusão no estudo; critérios pré-definidos para atribuição causal dos efeitos patogenéticos relatados), a média global dos escores dos ensaios patogenéticos homeopáticos analisados foi de 5,65, com amplo predomínio de estudos de baixa qualidade metodológica (41,5\% com escore $4 ; 34,5 \%$ com escore $5-6 ; 14 \%$ com escore $7-8 ; 4,5 \%$ com escore $9-10 ; 4,5 \%$ com escore 12 ; $1,0 \%$ com escore 13 ).

Assumindo valor ímpar na validação dos resultados das EPHs, os "critérios de atribuição causal dos efeitos patogenéticos" são imprescindíveis para que os sintomas relatados sejam considerados 'manifestações patogenéticas da substância experimentada' (e não 'sintomas comuns do experimentador'), pois traduzem as 'características próprias' dos efeitos patogenéticos da experimentação de substâncias dinamizadas. Descritos inicialmente por Riley ${ }^{18}$, são os seguintes: a) ocorrência pouco tempo depois do uso do medicamento; b) intensidade do sintoma; c) duração do sintoma; d) peculiaridade ou originalidade do sintoma (idiossincrásico); e) convicção íntima do voluntário de que o sintoma foi causado pelo medicamento; f) comparação com sintomas produzidos pelo placebo; g) desaparecimento de sintomas antigos ou atuais durante o ensaio; h) incidência do sintoma em mais de um voluntário (confirmação em outros voluntários); i) associação de modalidades ou sintomas concomitantes; j) reaparecimento do sintoma após reexposição.

Avaliando os quatro componentes utilizados na avaliação do IQM, os autores descrevem que a "randomização" foi descrita em apenas 15 estudos $(10 \%)$, a maioria na última década do levantamento. O "mascaramento" dos experimentadores foi descrito em 83 estudos (53\%), o dos supervisores em 51 estudos (33\%) e o duplo-mascaramento em 41 estudos (26\%), enquanto que o mascaramento exclusivo dos voluntários ocorreu em 33 estudos (21\%). Os "critérios de inclusão/ exclusão" não foram citados em $78 \%$ das publicações; quando ocorreram, $94 \%$ se basearam na história clínica, $53 \% \mathrm{em}$ exames complementares e $11,7 \%$ tanto na aplicação de questionários de qualidade de vida quanto na aplicação de questionários psicológicos. A avaliação do estado de saúde antes da admissão dos voluntários não foi relatada em $65 \%$ deles.

Em 134 publicações (86\%) não foram descritos "critérios de atribuição causal dos efeitos patogenéticos". Dentre os critérios descritos nos estudos de melhor qualidade, predominou a incidência do sintoma em mais de um voluntário (33\%), seguido da intensidade do sintoma $(28 \%)$ e sua peculiaridade $(28 \%)$. A incidência de efeitos patogenéticos foi observada em $98 \%$ das publicações levantadas e em $84 \%$ dos experimentadores, com uma média de 7,3 sintomas/ voluntário, estando inversamente associada com a qualidade metodológica dos estudos: estudos de qualidade superior produziram menos efeitos patogenéticos quando comparados a ensaios de baixa qualidade.

Em torno de $75 \%$ das publicações, os efeitos patogenéticos ocorreram na primeira semana após a ingesta inicial do medicamento, apesar de terem surgido relato de sintomas com aparecimento tardio, muitas semanas após o início do estudo, em 36 publicações citadas. Em geral, os sintomas eram de curta duração (horas a poucos dias), sem menção da intensidade do fenômeno (indicador de baixo grau de sofrimento ou desconforto, segundo análise dos autores da revisão). Em relação às características e tamanho da amostra, a maioria dos voluntários era composta por estudantes de cursos de homeopatia (graduação, pós-graduação ou aprimoramento), com uma média de 18 experimentadores por estudo (mediana de 15). A duração dos estudos foi bastante variada, com uma média de 82 dias (mediana de 44 dias). A duração do estudo apresentou relação direta com o número médio de efeitos patogenéticos por voluntário e relação inversa com a qualidade metodológica do mesmo.

Quanto ao desenho dos ensaios patogenéticos analisados na revisão, a maioria apresentava "modelos quase experimentais" do tipo "antes e depois", com ou sem grupos controle que utilizassem placebo. Dentre os 47 estudos $(30 \%)$ que incluíram período de observação prévia (wash-out period), 22 fizeram uso de placebo contra 25 que o desprezaram. A tendência mais recente indica a aplicação de estudos experimentais randomizados e placebos-controlados, 14 deles com cruzamento (crossover). Em 56 estudos (36\%) foi usado grupo comparativo (placebo-controlado), sem citação da utilização do placebo como parâmetro de referência na manifestação de efeitos patogenéticos. O placebo foi usado com finalidades distintas: controle para comparação (duplo-cego completo), instrumento de conscientização dos voluntários e para eliminar sintomas semelhantes ocorridos no grupo ativo. Estudos de melhor qualidade metodológica relatam o uso de placebo, período de pré-observação e critérios de atribuição causal aos efeitos patogenéticos.

Em relação às substâncias experimentadas nos estudos levantados, 75 eram do reino vegetal, 29 do reino animal, 18 do reino mineral, 14 eram substâncias químicas compostas e 11 eram drogas convencionais. Em mais de $50 \%$ dos ensaios foram experimentadas substâncias cujos efeitos patogenéticos homeopáticos eram desconhecidos, tendo como critérios de seleção os efeitos medicinais e tóxicos no estado bruto. Diversas dinamizações foram utilizadas nos estudos, mas os registros não relacionaram esta variável com os efeitos patogenéticos em si, tanto no aspecto qualitativo quanto no quantitativo. Numa avaliação geral, ensaios patogenéticos homeopáticos com uso exclusivo de dinamizações acima da $12 \mathrm{cH}$ produziram 6,2 
sintomas/experimentador, enquanto aqueles que utilizaram dinamizações abaixo da $6 \mathrm{cH}$ geraram, em média, 8,9 efeitos patogenéticos.

Em geral, os ensaios patogenéticos mostraram-se bastante seguros, com poucos relatos de abandono e sem registros de riscos graves à saúde, embora tenha sido descrita uma elevada incidência de alterações somáticas e psíquicas nos experimentadores. Apesar destas conclusões e da importância que a idiossincrasia desempenha nas manifestações patogenéticas, entendemos que a posologia está diretamente relacionada à exacerbação de sintomas patogenéticos, ratificada pelas agravações homeopáticas da prática clínica homeopática diária.

\section{Propostas de protocolos de experimentação patogenética homeopática em humanos}

No Brasil, modelos de experimentação patogenética homeopática em humanos foram desenvolvidos ao longo das últimas décadas ${ }^{19-25}$, com mudanças evolutivas que culminaram na criação do "Protocolo Nacional de Experimentação Patogenética Homeopática em Humanos"26 pela Comissão de Pesquisa (Subcomissão de Experimentação Patogenética) da Associação Médica Homeopática Brasileira (AMHB).

Com algumas modificações, este modelo foi aplicado junto às Entidades Formadoras Homeopáticas Brasileiras (responsáveis pelos cursos de pós-graduação lato sensu em homeopatia) no sentido de ratificar os efeitos citados em experimentações anteriores, ampliar o conhecimento das propriedades curativas de novos medicamentos e auxiliar no aprendizado homeopático, entendendo-se que as vivências pessoais dos efeitos despertados por ultradiluições homeopáticas nos 'alunosmédicos experimentadores' assumem caráter didático impar. Como premissas básicas, apresenta os seguintes aspectos:

$>$ Deverá ser utilizada uma substância de origem e propriedades físico-químicas conhecidas, que será experimentada em diferentes dinamizações (potências) em um estudo duplo-cego, entremeadas com placebo que deverão apresentar as mesmas características de apresentação, aspecto, sabor e odor que as substâncias dinamizadas;

> Será utilizado um grupo controle, ao qual somente será oferecido placebo, possibilitando a comparação entre grupos;

$>$ O placebo será utilizado também no experimentador, segundo o conceito de que o melhor controle do experimentador é ele mesmo, possibilitando assim a comparação do experimentador consigo mesmo (intraindividual) e em um mesmo grupo (intragrupos);

$>$ Cada experimentador receberá potências e placebos de acordo com esquema (randomização) montado pela Equipe de Elaboração da Pesquisa, única a conhecer a substância a ser pesquisada e o código das dinamizações e placebos;

> A pesquisa será encaminhada pelo Coordenador Geral da Experimentação, que será auxiliado em suas tarefas por um Coordenador Local da Experimentação e os respectivos Diretores de Grupo e Diretores Clínicos;

$>$ Os candidatos a 'experimentador sadio' somente serão considerados aptos após período de auto-observação utilizado para elaboração da ficha clínica, entrevista, exames clínicos e subsidiários, e aprovação pelos responsáveis da pesquisa;

$>$ O critério de aprovação utilizado permite a inclusão de voluntários com pequenas mazelas perfeitamente conhecidas, desde que não ultrapasse o estádio 1 da Classificação Internacional de Doenças;

$>$ A experimentação propriamente dita somente poderá ser iniciada após ter sido aprovada por um 'Comitê de Ética em Pesquisa’ da Instituição onde será realizada;

> De acordo à Resolução 196 de 10/10/1996, do Ministério da Saúde/ Conselho Nacional de Saúde, que ordena as diretrizes e normas regulamentares de pesquisas envolvendo seres humanos, todos os experimentadores deverão assinar uma Declaração de Conhecimento do Protocolo e de Consentimento Livre e Esclarecido;

> Iniciada a experimentação, os experimentadores serão entrevistados semanalmente (ou quinzenalmente) por um Diretor Clínico, que se reunirá quinzenalmente com seu Diretor de Grupo para discutir os sintomas relatados;

> Analisados e bem identificados, os sintomas serão classificados em sintomas novos (nunca sentidos pelo experimentador), sintomas habituais modificados, sintomas habituais não modificados, sintomas pouco habituais não modificados e sintomas antigos que retornaram, sendo então enviados ao Coordenador Local da Experimentação para revisão, análise e encaminhamento à Equipe de Apoio Local para tabulação dos dados;

> Após o término da experimentação por todos os voluntários, a Equipe de Elaboração da Pesquisa apresentará a identidade da substância experimentada e o esquema de experimentação (aleatorização dos experimentadores e dos frascos utilizados).

> Desde a introdução da disciplina optativa "Fundamentos da Homeopatia (MCM0773)" no currículo da graduação da Faculdade de Medicina da Universidade de São Paulo (FMUSP), vimos desenvolvendo um modelo de "Experimentação Patogenética Homeopática Breve", aprovado pela Comissão de Ética para Análise de Projetos de Pesquisa do Hospital das Clínicas da Faculdade de Medicina da Universidade de São 
Paulo (CAPPesq-HCFMUSP) e oferecido de forma optativa e voluntária aos estudantes participantes da disciplina, como método de aprendizado qualitativo e fenomenológico dos pressupostos homeopáticos ${ }^{27-31}$.

Observando em si mesmos e/ou em seus colegas a propriedade das dinamizações homeopáticas suscitarem efeitos patogenéticos (efeitos primários ou adversos) das diversas categorias (mentais, gerais e físicos) em indivíduos sadios, assim como estimularem uma resposta curativa (ação secundária ou reação homeostática) em perturbações pré-existentes, com a posterior confirmação de que estas manifestações sintomáticas estão descritas em experimentações patogenéticas prévias da mesma substância dinamizada (Matérias Médicas Homeopáticas), os 'estudantesexperimentadores' aumentam a credibilidade na proposta científica do modelo homeopático. Nesta proposta didática, traçamos como premissas os seguintes aspectos:

$>$ O método de experimentação patogenética homeopática breve proposto é de dose única semanal (máximo de 4 doses) de placebo ou medicamento homeopático conhecido na dinamização $30 \mathrm{cH}$, sem que os experimentadores tenham conhecimento do grupo em que estão alocados e da substância ingerida (randomização dos grupos e mascaramento dos experimentadores). Após 4 semanas de observação, é realizado o cruzamento da substância ingerida (ensaio clínico cruzado ou sequencial; cross-over), observando-se os efeitos por mais 4 semanas;

$>$ Após o período de dois meses de experimentação e o relato das observações individuais, tanto os grupos quanto o nome do medicamento experimentado são revelados, procedendo-se ao estudo da experimentação patogenética homeopática prévia do mesmo medicamento, buscando-se as analogias e semelhanças com os sintomas despertados em ambas as experimentações;

$>$ Utilizando um diário de anotações, os estudantes-experimentadores relatam os prováveis efeitos patogenéticos em linguagem descritiva, observando as diversas modalidades sintomáticas (tipo, localização, horário, lateralidade, concomitantes, etc.), mencionando o tempo de surgimento após a ingestão do medicamento e o período de duração de cada sintoma;

> Os sintomas também são identificados segundo a classe de manifestação despertada: sintoma comum (s.c.), de tipo, intensidade e frequência habituais; retorno de sintoma antigo (r.s.a.), que há muito tempo não se manifestava; exacerbação de sintoma existente ou agravação homeopática (agrav.); ação curativa, com a melhora ou desaparecimento de sintoma existente (ef. $2^{\text {ário }}$; sintoma novo (s.n.), de tipo, intensidade e frequência incomuns, correspondente ao efeito primário ou patogenético da substância;

$>$ Todos os estudantes-experimentadores assinam Termo de Consentimento Livre e Esclarecido aprovado pela CAPPesq-HC-FMUSP. Na referida revisão sistemática cinquentenária dos ensaios patogenéticos homeopáticos, Dantas et al. ${ }^{16,17}$ sugerem algumas estratégias e delineamentos que deveriam ser incorporados aos desenhos de estudos futuros, a fim de que os erros sistemáticos possam ser minimizados e os efeitos patogenéticos provocados pelo medicamento testado tenham maior consistência científica:

> Estudo duplo-cego, randomizado, placebo-controlado, com definição prévia de critérios de inclusão e exclusão dos voluntários (na busca de indivíduos 'aparentemente saudáveis'), assim como critérios pré-definidos para 'atribuição causal dos efeitos patogenéticos dos medicamentos experimentados';

> Aplicação do método duplo-cego completo, com comparação intraindividual dos sintomas surgidos na experimentação do medicamento dinamizado e do placebo;

> Período de pré-observação dos voluntários (com ou sem placebo), com avaliação clínica e levantamento de sintomas e características próprias da individualidade, para comparação e exclusão dos efeitos patogenéticos semelhantes surgidos posteriormente na experimentação;

$>$ Evitar relação eticamente questionável de subordinação dos experimentadores;

$>$ Balanceamento dos grupos em termos de gênero e amostra representativa e suficiente;

$>$ Evitar o registro das mudanças e a supervisão excessivamente rígida (registros e entrevistas diárias) sugeridos por Hahnemann, que podem resultar numa captação exagerada de efeitos patogenéticos durante a experimentação;

> Utilizar ensaios clínicos controlados, com cruzamento intrapessoal mascarado do placebo e da substância ativa (cross-over), permitindo que um número maior de experimentadores participe do estudo, com maior probabilidade de manifestação de sintomas idiossincrásicos. Nestes casos, no cruzamento das substâncias, um período sem medicamento deve ser considerado, minimizando os efeitos residuais da substância ativa, que poderão adicionar sintomas patogenéticos falsopositivos no período de experimentação do placebo;

$>$ Delineamento experimental com duplo cruzamento e com análise da 'atribuição causal dos efeitos patogenéticos' em 3 fases sucessivas, conforme aplicado nas experimentações patogenéticas homeopáticas do Acidum malicum e do Acidum ascorbicum ${ }^{32}$.

Com o objetivo de elaborar um "Protocolo de Experimentação Patogenética Homeopática em Humanos" que possa ser utilizado de forma ampla e uniforme, utilizamos os desenhos de estudos citados anteriormente como referência, construindo um modelo híbrido que englobe os melhores quesitos das diversas iniciativas da experimentação patogenética homeopática em humanos. 


\section{OBJETIVOS DO ESTUDO}

Buscando uniformizar e aprimorar a experimentação patogenética homeopática em humanos segundo os sucessos e as falhas metodológicas apresentadas em estudos anteriores, este protocolo foi elaborado com o rigor científico de um ambiente acadêmico-hospitalar, propondo, inclusive, a utilização de exames complementares para ampliar o espectro de efeitos patogenéticos mensurados através de métodos diagnósticos laboratoriais e por imagem.

Este protocolo poderá ser utilizado para revisar e ampliar os efeitos patogenéticos de substâncias experimentadas previamente segundo metodologias diversas, propiciar o aumento do acervo de substâncias experimentadas segundo o modelo homeopático, pesquisar outras variáveis (doses, potências, escalas e métodos de dinamização, etc.) que possam influenciar no despertar de sintomas patogenéticos durante a EPH e acrescentar a possibilidade da vivência da experimentação patogenética homeopática na formação de estudantes de medicina, médicos e demais profissionais de saúde participantes dos ensaios.

\section{DESCRIÇÃO DO ESTUDO}

O estudo consistirá de duas fases: Fase 1 (período de seleção, auto-observação, coleta de exames subsidiários e esclarecimento dos experimentadores, com a duração de 2 meses) e Fase 2 (ensaio clínico randomizado cruzado ou sequencial, duplo-cego, placebo controlado, com a duração de 6-12 meses, acompanhado em visitas quinzenais).

Fase 1 (período de seleção, pré-observação, coleta de exames subsidiários e esclarecimento dos experimentadores, com duração de 2 meses)

De 10 a 30 experimentadores (E1 a E30) deverão satisfazer todos os critérios (inclusão/exclusão) definidos no protocolo. Para ser aceito como experimentador, o candidato deverá estar em bom estado de saúde física e mental, permitindo-se, no máximo, pequenos distúrbios perfeitamente conhecidos e que não necessitem de medicação para manterem-se silenciosos ('experimentador aparentemente saudável'). Durante a experimentação, os experimentadores deverão manter seus hábitos e atividades regulares, sem alterações significativas (atividade física e mental, alimentação, sono, produtos de higiene, etc.) que altere seu estado geral.

Na visita 1 (semana 0 ), satisfeitas estas características iniciais de inclusão, os voluntários serão esclarecidos sobre o referido protocolo de experimentação patogenética homeopática e assinarão o "Termo de Consentimento Livre e Esclarecido - TCLE". Durante o período inicial de préobservação (15 dias), o candidato a experimentador deverá preencher a ficha de "História Clínica Geral e Homeopática" (Anexo I) preparada para esta experimentação segundo os ditames da semiologia clássica ${ }^{33}$ e homeopática ${ }^{34}$, buscando identificar e relatar qualquer sinal ou sintoma que tenha ocorrido (últimos 12 meses) ou possa ocorrer de forma esporádica ou regular, a fim de poder distinguir possíveis manifestações patogenéticas (sintomas novos) que surjam durante a experimentação da substância selecionada.

Nesta auto-observação, juntamente com os 'aspectos físicos e orgânicos' comuns à anamnese ou história clínica clássica, o experimentador também deverá identificar e descrever os 'aspectos mentais' (características psíquicas e emocionais da sua personalidade e do seu caráter) e os 'aspectos gerais' (desejos e aversões alimentares; características do sono e dos sonhos; aspectos da transpiração e da febre; relação com o clima; lateralidade das manifestações sintomáticas; horário de manifestação dos distúrbios; fatores gerais de agravação ou melhoria dos sintomas; etc.) da sua individualidade, fundamentais para a avaliação semiológica homeopática.

Na visita 2 (semana 2), após as duas semanas iniciais de auto-observação, todos os candidatos serão entrevistados pelos investigadores envolvidos no estudo, denominados 'Diretores Clínicos da Experimentação' [médicos que realizarão as avaliações clínicas (geral e homeopática), complementando os dados da ficha de "História Clínica Geral e Homeopática" preenchida pelos candidatos e aplicando o "Exame Clínico Geral e Homeopático"], a fim de que possam ampliar os dados semiológicos dos candidatos e emitir o parecer sobre a permanência dos mesmos no estudo ('experimentadores aparentemente saudáveis'). Ao longo de toda a experimentação, cada experimentador será acompanhado por um mesmo médico ('Diretor Clínico'), em visitas quinzenais (ou semanais, dependendo da necessidade).

A anamnese homeopática será indispensável para o levantamento de hipóteses de medicamentos homeopáticos com características semelhantes aos prováveis experimentadores, a fim de que possam ser utilizados durante o estudo naqueles casos em que os efeitos patogenéticos das substâncias experimentadas mostrem-se demasiadamente incomodativos e devam ser 'antidotados', assim como nas possíveis intercorrências que necessitem terapêutica medicamentosa.

Considerado em condições satisfatórias, o candidato a participar da experimentação colherá os "Exames Complementares de Rotina" e outros que o pesquisador julgar conveniente, a fim de descartar qualquer anormalidade que o impeça de continuar no estudo e apresentar um perfil de exames subsidiários (bioquímica sanguínea, imagens, etc.) que permita comparações futuras com possíveis alterações secundárias à experimentação patogenética homeopática.

Após a verificação dos resultados dos exames complementares, caso continue apresentando condições favoráveis para participar da experimentação ('experimentador aparentemente saudável'), ele será incluído no estudo e iniciará a Fase II após completar o período de dois 
meses iniciais de auto-observação (semana 8), durante o qual deverá continuar se observando e complementando os dados levantados inicialmente nas fichas clínicas (aspectos mentais, gerais e físicos comuns à sua individualidade).

Fase 2 (ensaio clínico randomizado cruzado ou sequencial, duplo-cego, placebo controlado, com duração de 6-12 meses, acompanhado em visitas quinzenais)

Após o término da Fase 1 (2 meses iniciais), os experimentadores (E1 a E30) serão alocados em esquemas de randomização prévia segundo a 'sequência de experimentação das substâncias' ou 'associação dos frascos' que contemplem a intercalação de 2 frascos da 'substância ativa ou medicamento' em 'dinamizações diferentes (M1 e M2) ou iguais (M1 ou M2)' [mesma substância dinamizada nas potências $12 \mathrm{cH}$ (M1) e/ou 30cH (M2)] com 2 frascos de placebo (P) ou substância inerte, perfazendo 4 frascos combinados aleatoriamente para cada experimentador.

Este esquema poderá contemplar outras dinamizações do mesmo medicamento e/ou um número maior de repetições de uma mesma dinamização, implicando numa duração maior do ensaio patogenético. Num projeto inicial, sugerimos a menor sequência possível de substâncias, utilizando 2 frascos de uma mesma 'substância ativa ou medicamento' numa mesma dinamização $(\mathrm{M})$ intercalados aleatoriamente com 2 frascos semelhantes de substância inerte ou placebo (P). Assim sendo, teremos quatro frascos idênticos que serão intercalados de forma aleatória durante o estudo.

Serão escolhidos profissionais sem vínculo com o estudo para realizar a alocação aleatória dos experimentadores na 'sequência de experimentação das substâncias' previamente estabelecidas. Apenas o 'Coordenador Geral da Experimentação’ terá conhecimento da substância a ser experimentada e da 'escala de aleatorização dos experimentadores', a fim de que possa orientar os 'Diretores Clínicos' em casos que assim o exijam.

$\mathrm{Na}$ visita 3 (semana 8), os experimentadores deverão satisfazer os critérios de inclusão/ exclusão do estudo e apresentar os resultados dos exames complementares condizentes com a condição de 'experimentador aparentemente saudável'. Após apresentar e discutir com o 'Diretor Clínico' as possíveis 'características ou sintomas pessoais comuns' observadas durante o segundo mês de auto-observação, complementando as fichas clínicas iniciais (geral e homeopática), cada experimentador receberá o frasco da primeira substância a ser experimentada (frasco 1), segundo a 'sequência de distribuição das substâncias' previamente aleatorizada, sendo orientado quanto à posologia a ser seguida (Dinâmica da Experimentação - Anexo II) e à forma de anotar as alterações observadas durante a experimentação (Diário de Experimentação - Anexo III).

Para cada frasco recebido (frascos 1, 2, 3 e 4), o experimentador deverá pingar durante os primeiros sete dias de experimentação 5 gotas da substância diretamente sobre a língua, duas vezes ao dia, respeitados os intervalos de 30 minutos de jejum, antes e após as doses. Em caso de surgimento de sintomas patogenéticos 'evidentes' ou 'marcantes', suspender as ingestas e observar a evolução dos fenômenos, anotando as mudanças detalhadamente (Diário de Experimentação - Modalização dos Sintomas - Anexo III).

Caso não observe o aparecimento de sintomas patogenéticos evidentes nos primeiros sete dias da experimentação, aumentar a repetição das doses ( 5 gotas sobre a língua) para 4 vezes ao dia, do $8^{\circ}$ ao $14^{\circ}$ dia ou até o surgimento de sintomas patogenéticos evidentes, quando as ingestas deverão ser interrompidas. Interromper a experimentação de cada frasco no $14^{\circ}$ dia. Caso não surjam sintomas, esperar mais 21 dias para recomeçar o mesmo processo com o frasco seguinte.

Em qualquer momento da experimentação, ao aparecerem sintomas patogenéticos marcantes, interromper a ingesta da substância, anotar os sintomas no "Diário de Experimentação" e discuti-los com o 'Diretor Clínico' na próxima visita. Desaparecido(s) o(s) sintoma(s), esperar mais 21 dias para retomar a experimentação com o frasco seguinte.

Caso haja dúvida da natureza patogenética dos sintomas surgidos (sintomas 'não evidentes' ou 'não marcantes'), persistir, enquanto continuar a dúvida, por mais 24 horas na ingesta das doses do frasco. As mulheres deverão evitar iniciar a ingesta das doses, de qualquer frasco, imediatamente antes e durante o período menstrual. Iniciar no primeiro dia após o término da menstruação. Repetir a mesma rotina até o último frasco, a menos que haja alguma mudança protocolar anunciada pelo 'Diretor Clínico'.

A experimentação poderá ser interrompida a critério do 'Coordenador Geral', quando se tratar de violação do protocolo ou quando a decisão visar o afastamento de um dos experimentadores (eventos adversos graves, violação do protocolo, etc.). Em caso de evento adverso grave que necessite tratamento prolongado, o experimentador deverá ser afastado da experimentação.

A experimentação poderá ser interrompida pelo experimentador quando este o desejar. Tal decisão deverá ser comunicada ao 'Diretor Clínico' que deverá comunicar o fato ao 'Coordenador Geral' e ao 'Comitê de Ética em Pesquisa da Instituição'. Intercorrências de menor monta, tais como quadros virais autolimitados, contusões leves, distúrbios digestivos, etc., se possível, não deverão ser medicadas. Em qualquer caso, a recomendação é a de que o experimentador faça contato imediato com o seu 'Diretor Clínico', a fim de que este possa decidir a conduta. Caso seja necessária alguma medicação (convencional ou homeopática) para essas situações, o experimentador poderá voltar à experimentação decorrido o prazo de 
30 (trinta) dias do desaparecimento dos sintomas ou da interrupção da medicação utilizada, desde que seu 'Diretor Clínico' o autorize, em consonância com o 'Coordenador Geral'.

Os sintomas e desconfortos advindos da experimentação tendem a desaparecer espontaneamente em breve período após a suspensão das doses, principalmente se isso for feito tão logo os sintomas apareçam, conforme determina este protocolo.

Todas as manifestações observadas serão descritas e anotadas com a 'linguagem do experimentador' (discurso do experimentador), a fim de que possam constituir o texto da Matéria Médica Pura da experimentação, desde que estes efeitos patogenéticos apresentem evidências sugestivas de estarem relacionados à substância ativa experimentada ('comparação intraindividual dos sintomas surgidos na experimentação do medicamento dinamizado e do placebo'; 'critérios de atribuição causal dos efeitos patogenéticos').

Na visita 4 (semana 10) e em todas as visitas quinzenais subsequentes, o experimentador será entrevistado pelo 'Diretor Clínico', que se encarregará de ler os sintomas observados durante a experimentação juntamente com os experimentadores, classificando-os em 'Sintomas Novos' (SN), 'Sintomas Habituais Modificados' (SHM), 'Sintomas Habituais Não Modificados' (SHNM), 'Sintomas Pouco Habituais Modificados' (SPHM), 'Sintomas Pouco Habituais Não Modificados' (SPHNM), 'Desaparecimento de Sintomas Habituais' (DSH) e 'Retorno de Sintomas Antigos' (RSA). Todo experimentador deverá ser instruído a comentar sobre seus sintomas apenas com seu 'Diretor Clínico' para evitar a contaminação dos outros participantes.

\section{POPULAÇÃO ESTUDADA}

\section{Critérios de inclusão}

Indivíduos que após orientação adequada sobre o ensaio patogenético homeopático, preencham corretamente o TCLE e recebam uma cópia do documento.

Profissionais da saúde, com idades entre 18-60 anos de idade, de ambos os sexos.

Indivíduos que preencham os pré-requisitos de 'experimentador aparentemente saudável' na Fase 1 do projeto, confirmados através da "História Clínica Geral e Homeopática", do "Exame Clínico Geral e Homeopático" e dos "Exames Complementares de Rotina".

Todos os indivíduos devem estar capacitados e habilitados a seguirem e aderirem ao esquema de visitas e à terapêutica instituída.

\section{Critérios de exclusão}

Mulheres grávidas ou lactantes.
Indivíduos que estejam utilizando medicamentos de uso contínuo nos últimos 6 meses.

Indivíduos que participaram de algum estudo clínico prévio num prazo menor de 6 meses.

Indivíduos que fizeram imunoterapia, tratamento homeopático, fitoterápico ou qualquer outra modalidade terapêutica nos últimos 6 meses.

Indivíduos com doença crônica ou episódios agudos repetitivos, constatados através de avaliação médica clínica e subsidiária (laboratorial, radiológica, etc.).

\section{Restrições a serem observadas}

Nenhuma pessoa envolvida diretamente com a administração do fármaco poderá participar do estudo como experimentador.

Voluntários com TCLE considerado incompleto não poderão iniciar o estudo.

O estudo deverá ser conduzido pelos mesmos investigadores acordados previamente no protocolo.

Os experimentadores deverão manter seus hábitos e atividades regularmente, sem mudanças significativas (atividade física e mental, alimentação, sono, produtos de higiene, etc.) que alterem seu estado geral, a fim de que os vieses de confusão possam ser minimizados ao longo da experimentação patogenética homeopática.

Os experimentadores estarão proibidos de utilizar quaisquer medicamentos, suplementos vitamínicos, minerais ou dietéticos durante o período de experimentação. Em caso de necessidade terapêutica por alguma intercorrência, o experimentador poderá retornar ao protocolo após período de metabolização da substância (wash-out).

\section{TRATAMENTO PRÉVIO E CONCOMITANTE}

Nenhum experimentador participante do estudo poderá receber concomitantemente qualquer medicação ou tratamento que não esteja acordada e registrada no protocolo, devendo realizar um período de wash-out (após uso da medicação) para ser reincluído no protocolo. Todas as medicações prévias ou concomitantes utilizadas nos seis meses anteriores ao estudo devem ser registradas, incluindo qualquer produto OTC (produto farmacêutico de venda livre), bem como sua posologia, via de administração, duração do tratamento e as razões para uso. Experimentadores que utilizarem quaisquer medicações que possam afetar o curso da experimentação serão afastados do estudo (violação do protocolo).

\section{NÚMERO DE EXPERIMENTADORES}

Conforme os critérios estabelecidos no protocolo, 10 a 30 indivíduos aparentemente saudáveis farão parte do grupo de experimentadores. A Fase 1 constará de um período de dois meses, onde os voluntários passarão por 
estágios de seleção, pré-observação de sintomas, coleta de exames subsidiários e esclarecimento do protocolo de experimentação patogenética homeopática. Na Fase 2, denominada experimentação patogenética homeopática propriamente dita, todos os indivíduos considerados 'aparentemente saudáveis' participarão de um ensaio clínico randomizado cruzado ou sequencial, duplo-cego, placebo controlado, intercalando a experimentação de 2 frascos de substâncias ativas (segundo o processo de dinamização homeopática) com 2 frascos semelhantes de substâncias inertes (placebos), por um período de 6-12 meses, acompanhados em visitas quinzenais. Os indivíduos considerados aptos para participar da experimentação deverão cumprir todos os requisitos do protocolo.

\section{DURAÇÃO DO ESTUDO}

O estudo será dividido em duas fases:

Fase 1: período de seleção, pré-observação, coleta de exames subsidiários e esclarecimento dos experimentadores, com duração de 2 meses;

Fase 2: ensaio clínico randomizado cruzado ou sequencial, duplo-cego, placebo controlado, com duração de 6-12 meses, acompanhado em visitas quinzenais.

\section{ESCOLHA E DISPENSAÇÃO DA SUBSTÂNCIA A SER EXPERIMENTADA}

Em todas as experimentações patogenéticas homeopáticas deverá ser utilizada uma substância de origem e propriedades físico-químicas conhecidas, que poderá ser experimentada em diferentes posologias e dinamizações, entremeadas aleatoriamente com placebos, que deverão apresentar as mesmas características de aspecto, sabor e odor das substâncias dinamizadas.

A substância será desconhecida de todos os participantes do projeto e conhecida apenas do 'Coordenador Geral da Experimentação'. A substância escolhida para a experimentação no protocolo será informada através de carta (adendo) à 'Comissão de Ética em Pesquisa' da Instituição antes do início do projeto, pelo 'Coordenador Geral da Experimentação'.

A origem da substância, seu critério de pureza e sua preparação inicial deverão estar bem caracterizados e descritos, tendo suas características citadas na Farmacopéia Brasileira $^{35}$ (no caso da experimentação de fármacos modernos dinamizados) ou na Farmacopéia Homeopática Brasileira $^{12}$ (no caso da experimentação de medicamentos homeopáticos clássicos).

Optando-se pela experimentação de fármacos modernos dinamizados ou qualquer outra substância com propriedades farmacodinâmicas e farmacocinéticas conhecidas, o 'Coordenador Geral da Experimentação' deverá incluir nos "Exames Complementares de Rotina" os exames subsidiários que possibilitem diagnosticar laboratorialmente prováveis manifestações patogenéticas da experimentação da substância dinamizada, seguindo as principais alterações fisiológicas (eventos adversos) que as substâncias em doses ponderais despertam nos indivíduos que as experimentam. Desta feita, estes exames serão colhidos semanal ou quinzenalmente.

As substâncias serão experimentadas na forma líquida (solução alcoólica a 70\%), dispensadas em frascos de $20 \mathrm{ml}$. Os frascos e o veículo das substâncias (ativa e placebo) serão idênticos. Sugerimos a utilização de dinamizações a partir da $12^{\mathrm{a}}$ potência da escala centesimal hahnemanniana $(12 \mathrm{cH})$, que apresentam concentrações inferiores a $10^{-24} \mathrm{M}$ da substância matriz (concentrações inferiores ao Número de Avogadro, com ausência de molécula-grama da substância matriz na preparação homeopática).

Conforme relatado anteriormente, um profissional sem vínculo algum com o estudo realizará a distribuição prévia e aleatória dos experimentadores nas 'sequências de experimentação das substâncias' (S1, S2, S3 e S4), conforme a ordem de entrada no protocolo (E1, E2, E3, E4, E5, etc.). Os frascos a serem utilizados pelos experimentadores em ordem crescente de experimentação (frascos 1, 2, 3 e 4) deverão estar codificados com o nome e/ou o número do experimentador (E1, E2, E3, E4, E5, etc.), para que nenhuma outra distinção seja possível. O esquema da randomização, que liga cada experimentador a uma sequência específica de frascos aleatorizada, só será conhecido pelo 'Coordenador Geral da Experimentação'.

A dispensação dos frascos das substâncias (dinamizada e placebo) será da responsabilidade de Laboratório ou Farmácia Homeopática conceituada (especificar nome, endereço e contato). Estes frascos serão numerados segundo aleatorização prévia e distribuídos aos experimentadores pelo mesmo profissional que realizou a randomização. Havendo necessidade de substituir ou repor alguma substância em uso para um experimentador envolvido no estudo, o fornecimento e distribuição seguirão os procedimentos acima descritos.

Toda medicação fornecida deverá ser estocada pelo experimentador em local apropriado, evitando umidade, calor e incidência de luz direta. Toda medicação deverá ser checada a cada visita, devendo o experimentador ser orientado a trazer o(s) frasco(s) em todas as visitas.

\section{EVENTOS ADVERSOS OU EFEITOS PATOGENÉTICOS HOMEOPÁTICOS}

Segundo a concepção clássica, um "evento adverso" é qualquer ocorrência indesejável, não apresentando, necessariamente, relação causal com o tratamento em estudo. Isto inclui quaisquer alterações psíquicas, gerais ou físicas apresentadas pelo indivíduo, relacionadas ou não ao uso do medicamento em estudo.

$\mathrm{Na}$ experimentação patogenética homeopática em 
humanos, estes eventos adversos constituem o desfecho primário da pesquisa (sintomas patogenéticos), desde que estejam relacionados à substância dinamizada experimentada, conclusão difícil de ser assumida, em vista dos sintomas habituais ou comuns do experimentador, indisposições passageiras e fortuitas (secundárias a aspectos alimentares, climáticos, medicamentosos, familiares, sociais, profissionais, etc.), efeito pacebo-nocebo, etc.

Os eventos adversos 'peculiares' e 'incomuns' surgidos após a experimentação da substância dinamizada, tanto nos aspectos qualitativos ou quantitativos, são definidos como 'efeitos primários' ou 'efeitos patogenéticos' que a substância despertou no experimentador aparentemente saudável, desde que o mesmo não esteja sob a influência de outros estímulos. Isto inclui qualquer alteração psíquica, geral e física (incluindo alterações em exames complementares) apresentada pelo indivíduo no curso da experimentação.

Para aumentar a 'validade interna' das manifestações patogenéticas observadas na experimentação, a fim de que possam ser empregadas com maior confiabilidade na prática clínica homeopática ('validade externa'), pode-se atribuir um grau de confiabilidade ou especificidade aos sintomas patogenéticos segundo o número de "critérios de atribuição causal" relacionado a cada sintoma. Com o intuito de incrementar as evidências da relação direta e causal entre a substância experimentada e os efeitos patogenéticos observados ("Validação dos Resultados da Experimentação Patogenética Homeopática"), além da constatação da ocorrência de um número desejável de "critérios de atribuição causal" nos sintomas citados, estamos propondo algumas escalas de classificação e pontuação (escores) para cada um destes fatores de análise (critérios), que poderão ser utilizados na 'pontuação do sintoma' quando forem confeccionados a matéria médica e o repertório da substância experimentada.

Numa experimentação patogenética homeopática cruzada ou sequencial, controlada por placebo, na qual os indivíduos experimentam de forma aleatória e mascarada a substância dinamizada e o placebo, efeitos patogenéticos que sejam despertados pelo placebo (descartando qualquer possível efeito residual de uma substância ativa experimentada anteriormente) serão considerados falsopositivos, anulando sintomas semelhantes que possam ser despertados durante a experimentação da substância ativa.

Para cada efeito patogenético serão registrados: datas de início e término do sintoma, duração, intensidade, efeito sobre a ingestão da substância em estudo (ex: interrupção ou descontinuidade da ingestão, número de doses, etc.), relação direta com a substância, ocorrência de acontecimentos ou mudanças marcantes na vida ou na rotina do indivíduo, etc.

Aspectos da manifestação patogenética como "intensidade", "duração", "relação temporal”, "convicção íntima do fenômeno", "incidência em mais de um experimentador", etc., consideradas como "critérios de atribuição causal" do experimentador com a substância em estudo, também serão avaliadas individualmente, recebendo pontuações específicas.

Outro aspecto importante se refere à "originalidade", "modalização" e "reprodutibilidade dos sintomas ou efeitos patogenéticos", que os caracterizam em mais ou menos idiossincrásicos, conforme a singularidade das manifestações observadas (Diário de Experimentação Modalização dos Sintomas - Anexo III).

Todos os efeitos patogenéticos que surgirem ao longo do estudo deverão ser registrados em um diário específico para este fim (Diário de Experimentação Anexo III).

\section{Classificação dos efeitos patogenéticos}

Durante a experimentação patogenética homeopática, diversos tipos de sintomas poderão ser observados, relacionados ou não à substância dinamizada, que serão classificados pelos experimentadores segundo as características abaixo:

- Sintomas Novos (SN);

- Sintomas Habituais Modificados (SHM): ‘agravação’ ou ‘desaparecimento’ do sintoma habitual;

- Sintomas Habituais Não Modificados (SHNM);

- Sintomas Pouco Habituais Modificados (SPHM): 'agravação' (ou 'desaparecimento', que só poderá ser confirmado num tempo maior de observação) do sintoma habitual;

- Sintomas Pouco Habituais Não Modificados (SPHNM);

- Desaparecimento de Sintomas Habituais (DSH);

- Retorno de Sintomas Antigos (RSA).

Os sintomas 'não modificados'('habituais' ou 'pouco habituais') terão pouca relação com os efeitos patogenéticos provocados pela substância nos experimentadores sadios, em vista de serem características comuns à individualidade em estudo. Os sintomas 'novos' ou 'modificados' ('habituais' ou 'pouco habituais') serão aqueles que poderão estar relacionados à substância experimentada, desde que cumpram os "critérios de atribuição causal" para serem considerados efeitos patogenéticos.

Cumprindo essas premissas, os 'sintomas novos' serão os típicos e inequívocos sintomas patogenéticos despertados em experimentadores verdadeiramente sadios, ou seja, que não apresentem qualquer manifestação sintomática, por mais leve e passageira que seja.

Os 'sintomas modificados' ('habituais' ou 'poucohabituais'), quando apresentarem aumento incomum na intensidade ou na frequência de manifestação, podem representar o que chamamos de "agravação homeopática", 
fruto da somatória do padrão sintomático comum do experimentador com o efeito patogenético de sintomas semelhantes da substância experimentada. O "retorno de sintomas antigos", suprimidos no passado e que retornam após a experimentação homeopática, está relacionado a esta mesma hipótese.

Após esta 'agravação inicial' dos sintomas do experimentador, também poderá ocorrer uma reação curativa (efeito secundário) do organismo no sentido de manter a homeostase interna. Desta forma, o "desaparecimento de sintomas habituais" ('sintomas curados') durante a experimentação patogenética homeopática, pode indicar uma resposta terapêutica homeopática (efeito curativo do organismo ou reação vital), fruto de uma similitude casual entre os sintomas do experimentador e os efeitos patogenéticos da substância dinamizada experimentada.

\section{Validação dos resultados da experimentação patogenética homeopática}

Com o intuito de incrementar as evidências da relação direta entre a substância experimentada e os efeitos patogenéticos observados, além da constatação da ocorrência de um número desejável de "critérios de atribuição causal" nos sintomas descritos, estamos propondo algumas escalas de classificação e pontuação (escores) para cada um destes fatores de análise (critérios), buscando uma forma de analisar quantitativamente os aspectos subjetivos e qualitativos da experimentação patogenética homeopática.

\section{patogenéticos \\ $\checkmark$ Critérios de atribuição causal para os efeitos}

Assumindo importância na validação dos resultados da EPH, os "critérios de atribuição causal" dos efeitos patogenéticos são indispensáveis para a aceitação do 'verdadeiro' ou 'mais provável' efeito patogenético da substância experimentada (evitando-se confusões com os sintomas comuns do experimentador e demais intercorrências), porque estes critérios traduzem as 'propriedades ou características próprias das manifestações patogenéticas' observadas na experimentação das substâncias dinamizadas. São eles:

- Confrontação do sintoma patogenético com sintoma semelhante produzido pelo placebo;

- Intensidade do sintoma;

- Duração do sintoma;

- Ocorrência do sintoma pouco tempo após a ingestão da substância dinamizada (associação temporal);

- Convicção íntima do experimentador de que o sintoma foi causado pela substância experimentada;
- Peculiaridade ou originalidade do sintoma (idiossincrasia);

- Associação de modalidades ou concomitantes ao sintoma comum (sintomas modalizados, individualizados ou particularizados);

- Incidência do sintoma em mais de um voluntário (confirmação em outros voluntários);

- Citação do sintoma em outras experimentações a mesma substância;

- Desaparecimento de sintomas habituais durante a experimentação (sintomas curados);

- Verificação de prováveis alterações fisiológicas, secundárias aos efeitos patogenéticos descritos, através de exames subsidiários.

Como citado inicialmente, alguns autores relacionam a validade interna e a credibilidade da manifestação patogenética citada (efeito patogenético 'verdadeiro') com o número de "critérios de atribuição causal" presentes em cada sintoma manifesto (Tabela 1).

Tabela 1. Classificação segundo o 'número de critérios de atribuição causal'

\begin{tabular}{l|l}
\hline Grau 0: Não relacionado & Não mencionados \\
\hline $\begin{array}{l}\text { Grau 1: Possivelmente } \\
\text { relacionado }\end{array}$ & Pelo menos um definido \\
\hline $\begin{array}{l}\text { Grau 2: Provavelmente } \\
\text { relacionado }\end{array}$ & 2-4 critérios definidos \\
\hline Grau 3: Relacionado & Mais de 4 critérios definidos \\
\hline
\end{tabular}

Podemos também atribuir 'escores quantitativos' ou 'graus de importância' aos "critérios de atribuição causal", segundo aspectos quali-quantitativos de análise dos mesmos.

$\checkmark$ Classificação da validade dos efeitos patogenéticos semelhantes despertados pelas substâncias ativa e placebo

Aplicação do método duplo-cego 'completo' citado inicialmente, com comparação intraindividual dos sintomas semelhantes surgidos na experimentação do medicamento dinamizado e do placebo, descartando da categoria de efeitos patogenéticos homeopáticos 'verdadeiros' os sintomas 'falso-positivos', ou seja, aqueles sintomas manifestos tanto na experimentação do placebo quanto na experimentação da substância ativa dinamizada.

Os prazos de 'descanso medicamentoso' (washout) após o término das manifestações patogenéticas e da experimentação de cada frasco, assim como os critérios de suspensão das ingestas tão logo se observem qualquer manifestação patogenética, devem ser estritamente respeitados, a fim de que não ocorra um efeito residual da 
Teixeira MZ. Protocolo de experimentação patogenética homeopática em humanos.

substância ativa dinamizada numa possível fase posterior de experimentação do placebo, evitando-se importante viés na aferição dos resultados (neste caso, um efeito patogenético 'verdadeiro' da substância ativa poderia contaminar uma fase subsequente de experimentação de substância inerte, caracterizando-o, numa comparação enviesada dos grupos, como um sintoma 'falso-negativo'). Em vista deste possível viés ou erro sistemático de confusão na análise, propomos uma atribuição de valores para as diversas modalidades desta ocorrência (Tabela 2).

Tabela 2. Classificação da validade dos efeitos patogenéticos semelhantes despertados pelas substâncias ativa e placebo

\begin{tabular}{l|l}
\hline Grau 0: Não relacionado & $\begin{array}{l}\text { Sintoma comum (não modalizado) observado quando a experimentação da substância } \\
\text { placebo antecedeu a substância ativa. }\end{array}$ \\
\hline Grau 1: Possivelmente relacionado & $\begin{array}{l}\text { Sintoma comum (não modalizado) observado quando a experimentação da substância ativa } \\
\text { antecedeu a substância placebo. }\end{array}$ \\
\hline Grau 2: Provavelmente relacionado & $\begin{array}{l}\text { Sintoma idiossincrásico ou modalizado observado quando a experimentação da substância } \\
\text { ativa antecedeu a substância placebo. }\end{array}$ \\
\hline Grau 3: Relacionado & $\begin{array}{l}\text { Sintoma idiossincrásico ou modalizado observado quando a experimentação da substância } \\
\text { ativa antecedeu a substância placebo em 2 frascos na mesma experimentação. }\end{array}$ \\
\hline
\end{tabular}

$\checkmark$ Classificação dos efeitos patogenéticos quanto à 'intensidade', 'duração', 'associação temporal' $e$ 'convicção íntima do experimentador'

A fim de quantificarmos a 'intensidade e a duração do sintoma', a 'associação temporal' e a 'convicção íntima do experimentador' como fatores de relações causais entre a substância experimentada e a manifestação patogenética, sistematizamos outras tabelas de classificação de valores (escores ou pontuação) para estes aspectos qualitativos de análise, que deverão ser respondidos pelo experimentador na avaliação de cada sintoma (Tabelas 3, 4 e 5).

Tabela 3. Classificação quanto à intensidade dos efeitos patogenéticos

\begin{tabular}{l|l}
\hline Grau 1: Leve & Sinal, sintoma ou evento perceptível, mas facilmente tolerado. \\
\hline Grau 2: Moderado & $\begin{array}{l}\text { Desconforto suficiente para provocar interferência nas atividades habituais, que obriga a suspensão imediata } \\
\text { da ingestão das doses e pode merecer intervenção caso o desconforto demore a cessar. }\end{array}$ \\
\hline Grau 3: Intenso & $\begin{array}{l}\text { Provoca limitação, com incapacidade de realizar atividades habituais ou interfere significativamente no } \\
\text { estado clínico, podendo estar relacionado ao excesso de doses ou à idiossincrasia individual, que obriga a } \\
\text { suspensão imediata da ingestão das doses e pode merecer intervenção caso o desconforto demore a cessar. }\end{array}$ \\
\hline
\end{tabular}

Tabela 4. Classificação quanto à duração e à frequência dos efeitos patogenéticos

\begin{tabular}{l|l}
\hline Grau 1: Leve & $\begin{array}{l}\text { Sintoma com duração inferior a uma hora e com um único episódio durante o período de experimentação do } \\
\text { frasco. }\end{array}$ \\
\hline Grau 2: Moderado & $\begin{array}{l}\text { Sintoma com duração superior a uma hora ou com mais de um episódio durante o período de experimentação } \\
\text { do frasco. }\end{array}$ \\
\hline Grau 3: Intenso & $\begin{array}{l}\text { Sintoma com duração superior a uma hora e com mais de um episódio durante o período de experimentação } \\
\text { do frasco. }\end{array}$ \\
\hline
\end{tabular}

Tabela 5. Classificação quanto à associação temporal e convicção íntima do experimentador

\begin{tabular}{l|l}
\hline Grau 0: Não relacionado & $\begin{array}{l}\text { Sem associação temporal ou a causa do evento foi identificada ou a substância não pode estar } \\
\text { implicada com base na convicção íntima do experimentador. }\end{array}$ \\
\hline Grau 1: Possivelmente relacionado & $\begin{array}{l}\text { Associação temporal ou convicção íntima do experimentador estabelecida; no entanto, outras } \\
\text { etiologias são possíveis. }\end{array}$ \\
\hline Grau 2: Provavelmente relacionado & $\begin{array}{l}\text { Associação temporal e convicção íntima do experimentador estabelecida; no entanto, outras } \\
\text { etiologias são possíveis. }\end{array}$ \\
\hline Grau 3: Relacionado & $\begin{array}{l}\text { Associação temporal e convicção íntima do experimentador estabelecida; o caso não é expli- } \\
\text { cado por outras etiologias. }\end{array}$ \\
\hline
\end{tabular}


$\checkmark$ Classificação dos efeitos patogenéticos quanto à 'peculiaridade', 'modalização', 'reprodutibilidade' $e$ 'desaparecimento de sintomas habituais (sintomas curados)'

Sintomas patogenéticos comuns apresentam menos evidências de atribuição causal com a experimentação da substância dinamizada do que sintomas raros, peculiares e característicos, sejam na originalidade (sintoma incomum, singular, especial, imprevisto, inexplicável, bizarro, ou extravagante) da manifestação em si (Ex.: medo de morte iminente) ou na adição de particularidades ou modalidades que o individualizam perante outras manifestações patogenéticas comuns (Ex.: dor de cabeça holocraniana versus dor de cabeça em pontada, na têmpora esquerda, que se irradia para o occipício). A tabela de "Modalização de Sintomas" encontra-se descrita no "Diário de Experimentação" (Anexo III e Tabela 6).

Tabela 6. Classificação quanto à originalidade (peculiaridade) e/ou modalização dos efeitos patogenéticos

\begin{tabular}{l|l}
\hline Grau 1: Leve & Sintoma com manifestação original ou uma modalização de sintoma comum. \\
\hline Grau 2: Moderado & Sintoma com manifestação original ê uma modalização sintomática. \\
\hline Grau 3: Intenso & Sintoma com mais de uma modalização sintomática. \\
\hline
\end{tabular}

Muitos ensaios clínicos patogenéticos priorizam este aspecto qualitativo do efeito patogenético ao aspecto quantitativo da simples repetição de sintomas comuns, por representarem importantes manifestações idiossincrásicas da individualidade humana, com elevado grau de hierarquia na individualização dos pacientes que buscam o tratamento homeopático. No entanto, a ocorrência de efeitos patogenéticos da mesma substância dinamizada em outros experimentadores, no mesmo ou em outro ensaio (reprodutibilidade), demonstra uma relação causal e direta que não pode ser desprezada (Tabela 7).

Tabela 7. Classificação quanto à reprodutibilidade dos efeitos patogenéticos

\begin{tabular}{l|l}
\hline Grau 1: Leve & Repetição do sintoma em outro ensaio patogenético homeopático da mesma substância dinamizada. \\
\hline Grau 2: Moderado & Repetição do sintoma em outro experimentador no mesmo ensaio patogenético homeopático. \\
\hline Grau 3: Intenso & $\begin{array}{l}\text { Repetição do sintoma em mais de um experimentador, em outros ou no mesmo ensaio patogenético } \\
\text { homeopático da mesma substância dinamizada. }\end{array}$ \\
\hline
\end{tabular}

O desaparecimento de sintomas habituais (sintomas curados) durante a EPH pode indicar uma resposta terapêutica homeopática (efeito curativo do organismo ou reação vital), fruto de uma similitude involuntária e casual entre os sintomas do experimentador e os efeitos patogenéticos da substância dinamizada (Tabela 8). Ele pode ser antecipado pela 'agravação homeopática' propriamente dita.

Tabela 8. Classificação quanto ao desaparecimento de sintomas habituais (sintomas curados)

\begin{tabular}{l|l}
\hline Grau 1: Leve & Desaparecimento de um sintoma habitual durante a experimentação. \\
\hline Grau 2: Moderado & $\begin{array}{l}\text { Desaparecimento de um sintoma habitual durante a experimentação, com confirmação deste efeito clínico } \\
\text { curativo em outras experimentações ou na literatura. }\end{array}$ \\
\hline Grau 3: Intenso & Desaparecimento de mais de um sintoma habitual durante a experimentação. \\
\hline
\end{tabular}

\section{$\checkmark$ Classificação quali-quantitativa dos efeitos} patogenéticos segundo os critérios de atribuição causal

Utilizando como parâmetro a classificação segundo o 'número de critérios de atribuição causal' citado inicialmente, propomos uma 'classificação quantitativa dos efeitos patogenéticos' segundo os critérios de atribuição causal, utilizando uma somatória de valores (Graus 1, 2 e 3) dos escores específicos para cada "critério de atribuição causal", segundo as tabelas anteriores (Tabela 9).

Tabela 9. Classificação quali-quantitativa dos efeitos patogenéticos segundo os critérios de atribuição causal

\begin{tabular}{l|l}
\hline Grau 1: Leve & Pontuação máxima em 1-2 critérios de atribuição causal definidos ou escore total $\leq 6$ pontos. \\
\hline Grau 2: Moderado & Pontuação máxima em 3-4 critérios de atribuição causal definidos ou escore total $>6$ pontos e $\leq 12$ pontos. \\
\hline Grau 3: Intenso & Pontuação máxima em mais de 4 critérios de atribuição causal definidos ou escore total $>12$ pontos. \\
\hline
\end{tabular}




\section{$\checkmark$ Avaliação complementar dos efeitos patogenéticos homeopáticos}

Todos os experimentadores realizarão "Exames Complementares de Rotina", a fim de mensurar possíveis alterações fisiológicas desencadeadas pelos efeitos patogenéticos homeopáticos.

De acordo ao conhecimento prévio dos efeitos fisiológicos da substância experimentada em indivíduos humanos, caberá ao 'Diretor Geral da Experimentação' acrescentar novas provas laboratoriais aos exames de rotina, com o intuito de quantificar possíveis alterações transitórias nas funções fisiológicas do organismo após a experimentação da substância dinamizada. Caso este seja o desfecho principal da experimentação patogenética homeopática, a coleta periódica dos exames deverá ser realizada durante toda a experimentação, priorizando ou não determinadas manifestações sintomáticas que possam estar relacionadas aos principais efeitos farmacodinâmicos da substância experimentada.

Qualquer alteração nos exames complementares associada à manifestação patogenética em questão assumirá grande magnitude (Grau 3) como fator de relação causal entre substância dinamizada e efeito patogenético homeopático.

\section{Notificação dos efeitos patogenéticos}

Todos os efeitos patogenéticos que surgirem ao longo do estudo deverão ser registrados em um diário específico para este fim (Diário de Experimentação Anexo III) e transcritos para uma "Ficha de Notificação dos Efeitos Patogenéticos" (Anexo IV) com todos os critérios de atribuição causal anteriormente citados e seus respectivos valores de escores.

\section{Monitorização de eventos adversos ou efeitos patogenéticos homeopáticos}

Os indivíduos que apresentarem eventos adversos ou efeitos patogenéticos homeopáticos serão acompanhados com avaliações clínicas e exames laboratoriais pertinentes determinados pelos pesquisadores.

Todos os eventos adversos ou efeitos patogenéticos homeopáticos precisam ser acompanhados até a resolução satisfatória ou estabilização do mesmo. Quaisquer ações adotadas e seus resultados deverão ser registrados na página apropriada da ficha clínica, assim como no prontuário do paciente. Os resultados laboratoriais devem ser arquivados no prontuário do mesmo.

Para todos os eventos adversos ou manifestações patogenéticas homeopáticas que exijam o afastamento do indivíduo do estudo, definitiva ou temporariamente, as avaliações clínicas e laboratoriais pertinentes serão repetidas, pelo menos semanalmente, até a resolução final ou estabilização do(s) evento(s).

\section{Orientações para o tratamento de eventos adversos ou efeitos patogenéticos homeopáticos}

Durante a EPH, se um experimentador apresentar um evento adverso ou efeito patogenético homeopático, a substância dinamizada deverá ser suspensa imediatamente, medida de segurança que permitirá a observação das manifestações patogenéticas subsequentes sem o risco de manifestações sintomáticas desagradáveis e prejudiciais à dinâmica habitual do experimentador.

No caso de manifestações patogenéticas incomodativas, fruto da superdosagem (repetição excessiva das doses ou continuidade de ingestão da substância dinamizada mesmo após o surgimento do efeito patogenético) ou da idiossincrasia particular, a suspensão do medicamento, na maioria dos casos, será suficiente para interromper o processo, observando-se melhora significativa dos sinais e sintomas no período subsequente.

Caso contrário, o experimentador deverá ser afastado do estudo e acompanhado periodicamente pelo 'Diretor Clínico' responsável, até o completo desaparecimento dos sintomas e a recuperação dos estados mental, geral e físico do indivíduo. Nestes casos, a introdução de um medicamento homeopático individualizado para o experimentador, escolhido na fase inicial do estudo, poderá ser utilizada com o intuito de 'antidotar' os efeitos patogenéticos intensos e incomodativos.

\section{DESCONTINUAÇÃO DO ESTUDO}

Experimentadores devem ser descontinuados do estudo, caso seja considerado necessário para a manutenção do seu bem-estar. A não aderência (violação) ao protocolo ou a ocorrência de um evento adverso ou efeito patogenético grave ou significante, incluindo alteração laboratorial, descontinuará o experimentador do estudo. Caso o experimentador seja afastado do estudo, a razão será adequadamente relatada no protocolo.

Em caso de descontinuação do estudo, devem ser realizados todos os exames e avaliações delineadas para a visita final. Todos os testes laboratoriais feitos na visita 1 devem ser repetidos. Caso algum resultado esteja fora dos limites da normalidade e seja considerado clinicamente significante, o experimentador deverá ser monitorado até o completo retorno à normalidade clínica e laboratorial. O registro final deverá ser preenchido pelo investigador. Eventos adversos ou efeitos patogenéticos homeopáticos devem ser acompanhados até a sua resolução. 


\section{ANÁLISE ESTATÍSTICA}

Todos os dados levantados no estudo serão analisados, segundo abordagens diversas.

\section{População}

Os experimentadores serão analisados segundo as variáveis de sexo, raça e idade.

\section{Análise dos efeitos patogenéticos homeopáticos}

Todos os efeitos patogenéticos serão analisados segundo os "critérios de atribuição causal", aplicando-se valores (escores) aos mesmos conforme preencham os requisitos anteriormente citados. Estas variáveis deverão ser utilizadas onde houver necessidade, agrupandose fatores ou covariantes quando os parâmetros de causalidade forem analisados.

\section{Matéria médica e repertório de sintomas homeopáticos}

Todos os efeitos patogenéticos homeopáticos verdadeiramente atribuídos à experimentação patogenética homeopática serão descritos na linguagem do experimentador e agrupados em capítulos de ordenação anatômico-funcional, conforme a classificação e ordenação das Matérias Médicas Homeopáticas clássicas. Estes efeitos patogenéticos poderão ser sintetizados em rubricas e incorporados aos Repertórios de sintomas homeopáticos.

\section{CONCLUSÕES}

O desenho proposto por Hahnemann para as EPHs foi um dos primeiros exemplos de pesquisa sistemática com medicamentos na história da medicina, servindo de substrato para a elaboração do primeiro ensaio randomizado e placebo-controlado, realizado em 1835 (Nuremberg, Bavária) ${ }^{36,37}$ com o objetivo de provar a ação de substâncias ultradiluídas $(30 \mathrm{cH})$ em seres humanos, como vimos fazendo junto aos estudantes de medicina desde a introdução da disciplina optativa de homeopatia na grade curricular da FMUSP ${ }^{27-31}$.

$\mathrm{Na}$ busca do aperfeiçoamento deste modelo de pesquisa clínico-farmacológica homeopática, utilizado há mais de dois séculos para averiguar o poder curativo dos medicamentos empregados segundo o princípio da similitude terapêutica, a necessidade de uniformização e sistematização metodológica é um consenso, estimulando o aprimoramento e a publicação de protocolos cada vez mais aperfeiçoados ${ }^{37-40}$, para serem disponibilizados a pesquisadores do mundo todo.

Por ser uma linha de pesquisa vital ao desenvolvimento do ensino, da pesquisa e da assistência homeopática, estamos sugerindo a uniformização e a sistematização da pesquisa patogenética homeopática brasileira em torno das linhas mestras deste protocolo ${ }^{11}$, solicitando a colaboração de todos, com críticas e sugestões, para o aperfeiçoamento do mesmo.

\section{ANEXO I. História clínica geral e homeopática}

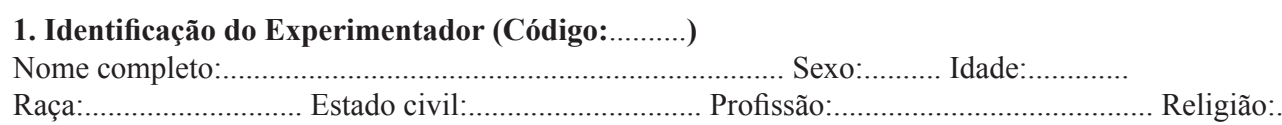

Data e Local de Nascimento:............................................................................... Data do Atendimento:

2. Queixas ou Sintomas Principais [descreva os 'sintomas habituais' (SH) e os 'sintomas não habituais' (SNH) que se manifestaram nos últimos 12 meses].

Sintomas Habituais (SH):

Sintomas Não Habituais (SNH):.

3. História dos Sintomas Atuais Modalizados (para cada sintoma citado anteriormente, indique a época de início (e término), a frequência e a duração, procurando particularizá-lo(s) segundo as diversas modalidades [intensidade (leve, moderada, intensa), localização, lateralidade (D, E, D与E), horário e época de aparecimento, fatores de agravação ou melhoria, sintomas concomitantes, sensações ou tipo de dor, etc.]. Seguir a Tabela para Modalização dos Sintomas (Apêndice 1). Repassar todos os sintomas para a Tabela de Sinais e Sintomas do Experimentador (Apêndice 2).

4. Revisão de Sistemas ou Aparelhos (ISDA) [todos os sintomas levantados nos próximos tópicos deverão ser modalizados (Apêndice 1) e relacionados na Tabela final (Apêndice 2)].

- Pele (aparecimento de erupções cutâneas; mudanças de coloração; alterações de pêlos, cabelos e unhas; caroços ou nódulos; úlceras; prurido; ressecamento ou oleosidade; temperatura; etc.) .....

- Cabeça (dores ou sensações; traumatismos cranianos; tontura; vertigem; erupções; etc.)

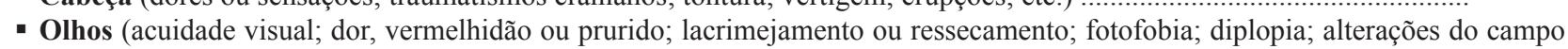
visual; visão turva; manchas ou escotomas; glaucoma; catarata; etc.) .... 
Teixeira MZ. Protocolo de experimentação patogenética homeopática em humanos.

Continuação

- Ouvidos (alterações da audição; dores; ruídos; prurido; erupções; infecções; secreção; etc.)

- Nariz e seios paranasais (dores; epistaxe; resfriados ou gripes de repetição; coriza; obstrução ou prurido nasal; espirros frequentes; sinusite; rinite; erupções; etc.)

- Boca e garganta (dores de dentes, boca ou garganta; rouquidão ou alterações da voz; sangramento gengival; estado dos dentes, da língua e das gengivas; boca seca; feridas ou úlceras; aftas; etc.)

- Pescoço (dores ou torcicolos; gânglios ou caroços; alterações da tireóide; erupções; etc.) ...

- Mamas (dores; nódulos; inchaço ou desconforto; secreção mamilar; ginecomastia; erupções; etc.)

- Sintomas respiratórios (tosse; expectoração; respiração; hemoptise; dor torácica; falta de ar; chiado ou ronco; asma; bronquite; enfisema; pneumonia; tuberculose; erupções no tórax; etc.)

- Sintomas cardíacos (dor torácica; falta de ar; ortopnéia; edemas; palpitações; sopros; etc.)

- Aparelho digestivo (dores abdominais; dificuldade ou dor à deglutição; queimação epigástrica; náuseas, vômitos, azia ou regurgitação; desejo, aversão ou intolerância alimentar (tipos de alimentos); digestão; hematêmese; hábito intestinal; tipos de fezes; hemorróidas; sangramento retal; eructações ou flatulência; tenesmo; ruídos intestinais; erupções; doenças prévias; hepatite; etc.)

- Sintomas urinários (dor ou ardência ao urinar; aumento ou diminuição da urina; urgência; alterações na cor e odor da urina; hematúria; jato urinário; infecções urinárias; cálculos renais; etc.)

- Problemas genitais masculinos (dores; hérnias; erupções, secreções ou feridas na região; próstata; tumores; DST; preferência, interesse, satisfação e problemas sexuais; etc.)

- Problemas genitais femininos (menarca; menopausa; ciclo e fluxo menstrual; metrorragia; cólica e tensão pré-menstrual; prurido, corrimento, feridas ou nódulos vaginais; DST; gestações, partos e abortos; métodos contraceptivos; preferência, interesse, satisfação e problemas sexuais; etc.)

- Problemas vasculares periféricos (claudicação intermitente; varizes; tromboses; cãibras; edemas; erupções e coloração de extremidades; etc.)

- Sintomas musculoesqueléticos (dores musculares ou articulares; rigidez, edema, calor ou vermelhidão em articulações; lombalgia; gota; 'reumatismo'; etc.)

- Sistema nervoso (síncope; desmaio; convulsões; tontura; paralisia; dormência, formigamento, diminuição ou aumento da sensibilidade; movimentos involuntários, tremores; força muscular; etc.)

- Problemas hematológicos (anemia; sangramentos fáceis; petéquias ou equimoses; etc.) ......

- Problemas endócrinos (intolerância ao calor ou ao frio; sudorese excessiva; polidipsia, polifagia, poliúria; problemas na tireóide; problemas ovarianos; outras alterações hormonais; etc.)

5. Sintomas Gerais e Constitucionais (febre; apetite e peso; disposição e ânimo; fraqueza ou cansaço; sensações diversas; edemas ou inchaços; predisposições; etc.)

- Sono [padrão do sono (perturbado, não reparador, interrompido, superficial, semi-consciente, profundo, prolongado, etc.); características do adormecer e do despertar; tipos de insônia; sonolência ou bocejos diurnos; manifestações durante o sono (apnéia, bruxismo, inquietude, falar, gritar, sobressaltos, sonambulismo, etc.); posição preferida ou impossível para dormir; etc.]

- Sonhos (tipos de sonhos repetitivos ou marcantes ao longo da vida)

- Desejos, aversões e intolerâncias alimentares (tipos de alimentos ou temperos; temperatura; consistência; etc.)

- Sede (quantidade; frequência; temperatura; tipos de líquidos; horários do dia; etc.)

- Aspectos da transpiração e demais secreções (local, tipo, cor, odor, temperatura; melhora ou piora os sintomas; etc.) ....

- Relações com o clima e o ambiente (calorento; friorento; melhora ou piora dos sintomas com frio, calor, vento, chuva, umidade, secura, cidade, praia, campo, montanha, etc.)

6. Sintomas Mentais ou Psíquicos (afetuosidade; ansiedade ou agitação; concentração, memória e compreensão; confiança ou segurança íntima; delírios, ilusões ou imaginações; desejos e vontades; emotividade; humor; nervosismo ou irritabilidade; medos, fobias; prazeres, alegrias ou satisfações; preocupações ou tensões; tristezas ou depressão; etc.)

- História biopatográfica [descreva as situações estressantes da sua vida que costumam desencadear distúrbios na saúde, sintomas ou doenças (Ex.: ansiedade; ciúme; cólera; decepção ou desapontamento; excitação; humilhação; indignação; mágoa; perda financeira; pesar; susto; etc.)]

7. Antecedentes Pessoais (doenças desde a infância; traumatismos, cirurgias, internações; medicamentos ou tratamentos utilizados ou em uso; alergias; imunizações; padrão do sono; etc.)

8. Hábitos e Vícios [tabagismo; álcool; drogas ilícitas; atividade física regular; alimentação (tipo, quantidade, desejos e aversões alimentares); uso de preservativos nas relações sexuais; etc.]

9. Antecedentes Familiares (estado de saúde, doenças e causa de morte de familiares; etc.)

10. História Pessoal, Familiar, Social e Profissional (problemas ou preocupações pessoais, familiares, sociais, financeiras, profissionais, etc.)

11. Outras Observações: 


\section{Anexo II. Dinâmica da experimentação}

Satisfeitas as condições iniciais do protocolo, a experimentação propriamente dita constará das seguintes etapas:

- Distribuição dos experimentadores pelos 'Diretores Clínicos', que juntos discutirão o "Diário de Experimentação" (Anexo III), sua dinâmica de registro e a necessidade de mantê-lo à mão todo o tempo. O período prévio de auto-observação facilitará em muito esta etapa;

- Distribuição aos experimentadores de um frasco numerado por vez, de forma sequencial (1, 2, 3 e 4), segundo as orientações deste protocolo, que deverá estar guardado em afastado de tudo que possa vir a exercer alguma influência como calor, campos eletromagnéticos, odores, etc.

- Uma vez determinado o frasco a ser utilizado, pingar 5 (cinco) gotas diariamente sobre a língua, duas vezes ao dia, respeitados os intervalos de 30 minutos antes e 30 minutos depois sem passar sólidos ou líquidos pela boca, nem haver fumado.

- Caso não ocorra aparecimento de sintomas patogenéticos em 7 dias, aumentar o número de tomadas para 4 vezes ao dia do $8^{\circ}$ ao $14^{\circ}$ dia, até o surgimento de sintomas. Caso não apareçam sintomas, interromper no $14^{\circ}$ dia.

- Caso não apareçam sintomas, esperar mais 21 dias até recomeçar o frasco seguinte.

- Ao aparecerem sintomas, interromper o uso de qualquer frasco, registrar os sintomas e discuti-los com o 'Diretor Clínico' após o registro. Desaparecido(s) o(s) sintoma(s), esperar mais 21 dias para reiniciar com o frasco seguinte.

- Caso haja dúvida da natureza dos sintomas surgidos (se está relacionada à substância ingerida ou a outros fatores), persistir, enquanto continuar esta dúvida, por mais 24 horas nas doses estipuladas.

- As mulheres evitarão iniciar qualquer frasco durante menstruação. Iniciarão no primeiro dia após o término da menstruação.

- Repetir a mesma rotina até o último frasco.

A experimentação poderá ser interrompida a critério do 'Diretor Clínico' e do 'Coordenador Geral da Experimentação', quando a decisão for de afastar um dos experimentadores. A experimentação poderá ser interrompida pelo experimentador quando este o desejar. Tal decisão deverá ser comunicada ao 'Diretor Clínico', que comunicará o fato ao 'Coordenador Geral da Experimentação' e este ao Comitê de Ética em Pesquisa da Instituição.

\section{Anexo III. Diário de experimentação}

Cada experimentador deverá carregar consigo o "Diário de Experimentação", a fim de anotar cada sintoma que vier a se manifestar, indicando com precisão a hora, o lugar, a modalidade, a sucessão, etc.

\section{A - Identificação}

Identificação do experimentador conforme o seu código na Ficha Clínica.

\section{B - Registro Geral}

Durante os diversos frascos experimentados, o experimentador terá que escrever com letra bem legível:

- Número do frasco.

- Dia, mês, ano e condições atmosféricas do início da experimentação de cada frasco.

- Mencione em números ordinais cada um dos dias de experimentação $\left(1^{\circ} \mathrm{dia}, \mathbf{2}^{\circ} \mathrm{dia}, 3^{\circ} \mathrm{dia}, 4^{\circ} \mathrm{dia}\right.$, etc. $)$, considerando o $1^{\circ}$ dia aquele em que se iniciou a ingestão da substância (para cada frasco) e, a partir daí, numerando sequencialmente.

- Identifique cada dia e horário em que as doses da substância foram ingeridas.

- As mulheres deverão sempre identificar os dias da menstruação.

- Quaisquer mudanças bruscas nos aspectos ambientais ou climáticos, alimentares, familiares, profissionais, psíquico-emocionais (estresse, brigas, provas, preocupações excessivas, etc.), etc., que possam criar uma interferência ou dúvida na observação das manifestações patogenéticas, devem ser anotadas no diário.

\section{C - Registro dos Sintomas (por ordem)}

- Os sintomas devem ser escritos em linguagem simples e natural, evitando-se linguagem técnica ou rebuscada. Os termos podem ser objetivos ou subjetivos, no sentido de que os experimentadores devem expressar-se de forma espontânea, sem especulações ou abstrações, com linguagem descritiva corrente, usando de analogias e evitando interpretações e afirmações infundadas.

- Definir um sintoma com um termo médico pode mudar a realidade. Este fato não é para decodificar a terminologia médica, mas para podermos estar seguros da realidade sintomática expressa pela reação dinâmica individual em sua totalidade.

- Anotar sempre a data e a hora de surgimento de cada sintoma, juntamente com os estados psíquico, geral e físico, e as condições atmosféricas.

- Identifique sempre a duração de cada sintoma: considerando horário e dia em que iniciou e terminou cada manifestação.

- Identifique a intensidade de cada sintoma em leve, moderado e intenso (vide "Ficha de Notificação dos Efeitos Patogenéticos Anexo IV"). 
Teixeira MZ. Protocolo de experimentação patogenética homeopática em humanos.

Continuação

- Anotar sempre os sintomas pela ordem de aparecimento.

D - Classificação dos Sintomas

Cada sintoma deve ser classificado segundo as definições abaixo:

- Sintomas Novos (SN)

- Sintomas Habituais Modificados (SHM): 'agravação' ou ‘desaparecimento' do sintoma habitual.

- Sintomas Habituais Não Modificados (SHNM)

- Sintomas Pouco Habituais Modificados (SPHM): 'agravação' (ou ‘desaparecimento', que só poderá ser confirmado num tempo maior de observação) do sintoma habitual.

- Sintomas Pouco Habituais Não Modificados (SPHNM)

- Desaparecimento de Sintomas Habituais (DSH)

- Retorno de Sintomas Antigos (RSA)

\section{E - Modalização dos Sintomas}

Cada sintoma deverá ser descrito de acordo ao interrogatório de modalização dos sintomas (vide "História Clínica Geral e Homeopática - Anexo I - Apêndice 1").

\section{F - Ficha de Notificação dos Efeitos Patogenéticos (Anexo IV)}

Todos os sintomas anotados no diário deverão ser transcritos, após apresentação ao 'Diretor Clínico', na “Ficha de Notificação dos Efeitos Patogenéticos" (Anexo IV).

\section{ANEXO IV. Ficha de notificação dos efeitos patogenéticos}

- Identificação do experimentador: $\mathrm{N}^{\mathrm{o}}$ do frasco:

- Data de aparecimento do sintoma: Duração do sintoma:

- Classificação do sintoma:

- Descrição do sintoma:

\begin{tabular}{|c|c|c|}
\hline $\begin{array}{l}\text { Presença dos } \\
\text { critérios }\end{array}$ & Critérios de atribuição causal para os efeitos patogenéticos & Escores \\
\hline & Confrontação do sintoma patogenético com sintoma semelhante produzido pelo placebo & \\
\hline & Intensidade do sintoma & \\
\hline & Duração do sintoma & \\
\hline & $\begin{array}{l}\text { Ocorrência do sintoma pouco tempo após a ingestão da substância dinamizada (associação } \\
\text { temporal) }\end{array}$ & \\
\hline & $\begin{array}{l}\text { Convicção íntima do experimentador de que o sintoma foi causado pela substância experi- } \\
\text { mentada }\end{array}$ & \\
\hline & Peculiaridade ou originalidade do sintoma (idiossincrasias) & \\
\hline & $\begin{array}{l}\text { Associação de modalidades ou concomitantes ao sintoma comum (sintomas modalizados ou } \\
\text { individualizados) }\end{array}$ & \\
\hline & Incidência do sintoma em mais de um voluntário & \\
\hline & Citação do sintoma em outras experimentações & \\
\hline & Desaparecimento de sintomas habituais durante a experimentação (sintomas curados) & \\
\hline & $\begin{array}{l}\text { Verificação de prováveis alterações fisiológicas } \\
\text { (alteração em exames subsidiários) }\end{array}$ & \\
\hline Total: & 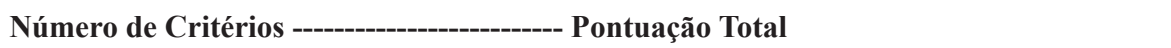 & Total: \\
\hline
\end{tabular}




\section{Apêndice 1. Interrogatório de modalização dos sintomas}

\section{Interrogatório de Modalização dos Sintomas (agravação/melhoria)}

1. Horários e Frequência.

2. Clima: ar livre, quente, úmido, sol, tormentas, calor da cama, etc.

3. Movimento: caminhar (lento, rápido, ao ar livre, etc.); subir, descer, etc.; viajar, bailar, mexer-se, fechar os olhos; exercícios físicos, repouso, etc.

4. Ocupações: trabalho físico ou mental; pensamentos, ler, escrever ou calcular; tocar piano, costurar, etc.; emprego sedentário, etc.

5. Posição: sentado, parado, deitado, agachado, ao levantar-se, ao dobrar-se, etc.

6. Lugar: em casa, ao ar livre, na cama, etc.; na escuridão, na multidão, etc.

7. Os outros: sozinho ou em companhia; conversando, falando, ao ser interrompido, etc.; ao ser tocado, por más notícias, etc.

8. Causa: sem causa ou por trivialidades; coisas horríveis, cenas marcantes, sonhos espantosos, etc.; por música, ruídos, etc.

9. Emoções: cólera, mágoa, pranto, depressão, lamentos, mortificação, reprovações, contradição, sustos, excitação, antecipação, etc.

10. Funções: comer, desjejum, almoço ou jantar; bebendo vinho, álcool, café, cerveja, bebidas frias ou quentes, etc.; ao evacuar, urinar, transpirar, etc.; pelo coito, menstruação, gravidez, amamentar, menopausa, etc.; ao dormir, despertar, etc.

Apêndice 2. Tabela de sinais e sintomas descritos pelo experimentador na Fase 1

\begin{tabular}{|l|l|}
\hline \multicolumn{2}{|c|}{ Sinais e Sintomas do Experimentador - Fase 1 } \\
\hline Sintomas Habituais (SH) & Sintomas Não Habituais (SNH) \\
\hline & \\
\hline & \\
\hline & \\
\hline & \\
\hline
\end{tabular}

\section{REFERÊNCIAS}

1. Teixeira MZ. Homeopatia: ciência, filosofia e arte de curar. Rev Med (São Paulo). 2006;85(2):30-43. Disponível em: http://medicina.fm.usp.br/gdc/docs/revistadc_88_30-43\%20 852.pdf.

2. Teixeira MZ. Evidências científicas da episteme homeopática. Rev Homeopatia (São Paulo). 2011;74(1-2):33-56. Disponível em: http://www.aph.org.br/revista/index.php/aph/article/ view/61/79.

3. Hahnemann S. Organon da arte de curar. 6a ed. Ribeirão Preto: Museu de Homeopatia Abrahão Brickmann; 1995.

4. Teixeira MZ. Efeito rebote dos fármacos modernos: evento adverso grave desconhecido pelos profissionais da saúde. Rev Assoc Med Bras. 2013;59(6):629-38. http://dx.doi. org/10.1016/j.ramb.2013.05.003.

5. Teixeira MZ. Similia similibus curentur: o princípio de cura homeopático fundamentado na farmacologia moderna. Rev Med (São Paulo). 2013;92(3):183-203.

6. Teixeira MZ. New homeopathic medicines: use of modern drugs according to the principle of similitude. Homeopathy. 2011;100(4):244-52. http://dx.doi.org/10.1016/j. homp.2011.01.002.
7. Teixeira MZ. 'New Homeopathic Medicines' database: a project to employ conventional drugs according to the homeopathic method of treatment. Eur J Integr Med. 2013;5(3):270-8. http://dx.doi.org/10.1016/j.eujim.2013.01.001.

8. Hahnemann S. Fragmenta de viribus medicamentorum positivis in sano corpore humano observatis. Lipsiae sumtu. Leipzig: JA Barth; 1805. Pt. 1 e 2. Available from: https:// archive.org/details/2088704.0001.001.umich.edu.

9. Hahnemann S. Materia medica pura. New Delhi: B. Jain Publishers; 1994. v.1, 2. Disponível em: https://archive.org/ details/materiamedicapu00dudggoog.

10. Hahnemann S. Chronic diseases. New Delhi: B. Jain Publishers; 1994. Disponível em: https://archive.org/details/ chronicdisease00hahn.

11. Teixeira MZ. Protocolo de experimentação patogenética homeopática em humanos. São Paulo: Marcus Zulian Teixeira; 2013. Disponível em: http://www.homeozulian.med. br/homeozulian_visualizarlivroautor.asp?id=11.

12. Farmacopéia Homeopática Brasileira. 3a ed. Brasília: Anvisa; 2011. Disponível em: http://www.anvisa.gov.br/hotsite/ farmacopeiabrasileira/conteudo/3a_edicao.pdf. 
13. Dantas F. How can we get more reliable information from homoeopathic pathogenetic trials? A critique of provings. $\mathrm{Br}$ Homeopath J. 1996;85:230-6. Disponível em: http://dx.doi. org/10.1016/S0007-0785(96)80007-X.

14. Dantas F, Fisher P. A systematic review of homoeopathic pathogenetic trials ('provings') published in the United Kingdom from 1945 to 1995. In: Ernst E, Hahn EG. Homoeopathy: a critical appraisal. London: ButterworthHeinemann; 1998. p. 69-97.

15. Dantas F, Rampes H. Do homeopathic medicines provoke adverse effects? A systematic review. Br Homeopath J. 2000;89(Suppl 1):S35-S38. Disponível em: http://dx.doi. org/10.1054/homp.1999.0378.

16. Dantas F. Revisão sistemática de ensaios patogenéticos homeopáticos [dissertação]. São Paulo: Escola Paulista de Medicina, Universidade Federal de São Paulo; 2006. Disponível em: http://www.bdtd.unifesp.br/tede//tde_busca/ arquivo.php?codArquivo=30.

17. Dantas F, Fisher P, Walach H, Wieland F, Rastogi DP, Teixeira $\mathrm{H}$, et al. A systematic review of the quality of homeopathic pathogenetic trials published from 1945 to 1995. Homeopathy. 2007;96(1):4-16. http://dx.doi.org/10.1016/j. homp.2006.11.005 .

18. Riley DS. Extracting symptoms from homoeopathic drug provings. Br Homeopath J. 1997;86:225-8. Disponível em: http://dx.doi.org/10.1016/S0007-0785(97)80049-X.

19. Marim M. Uma abordagem em experiência patogenética II. Rev Homeopatia (São Paulo). 1992;57(1-4):29-132.

20. Marim M. Uma abordagem em experiência patogenética. Rev Homeopatia (São Paulo). 1988;53(1):4-62

21. Sociedade Gaúcha de Homeopatia. Curso de Especialização em Homeopatia. Hydrocianic acidum. Rev Homeopatia (AMHB). 1997;1(1):66-80.

22. Vieira AAL. Patogenesia como método de ensino em homeopática. Rev Homeopatia (AMHB). 1997;1(1):10814

23. Associação Médica Homeopática Brasileira. Comissão de Pesquisa. Brosimum gaudichaudii: experimentação pura. São Paulo: Editora Organon; 1998.

24. Associação Médica Homeopática Brasileira. Comissão de Pesquisa. Brosimum gaudichaudii. Rev Homeopatia (AMHB). 1999; 3: 76-111.

25. Associação Médica Homeopática Brasileira. Comissão de Pesquisa. Bothrops jararacussu. Rev Homeopatia (AMHB). 1999;3:47-74.

26. Associação Médica Homeopática Brasileira. Comissão de Pesquisa. Protocolo de experimentação patogenética homeopática em humanos. Belo Horizonte; 2005.

27. Teixeira MZ. Experimentação patogenética homeopática breve como método didático. Rev Homeopatia (São Paulo).
2004;69(1-4):63-76

28. Teixeira MZ. Brief homeopathic pathogenetic experimentation: a unique educational tool in Brazil. Evid Based Complement Alternat Med. 2009;6(3):407-14. http://dx.doi.org/10.1093/ ecam/nem 128 .

29. Teixeira MZ. Experimentação patogenética homeopática breve como método didático. In: Anais do $5^{\circ}$ Congresso Paulista de Educação Médica, Botucatu, SP, 2006.

30. Teixeira MZ. Utilização da experimentação patogenética como metodologia de ensino da homeopatia. In: Anais do $46^{\circ}$ Congresso Brasileiro de Educação Médica, Salvador, BA, 2008.

31. Teixeira MZ. Results of swallowing mass overdose of homeopathic medicines in United Kingdom: scepticism or prejudice? Int J High Dilution Res. 2010;9(30):3-4. Available from: http://www.feg.unesp.br/ ojs/index.php/ijhdr/article/ viewFile/374/412.

32. Fisher P, Dantas F. Homeopathic pathogenetic trials of Acidum malicum and Acidum ascorbicum. Br Homeopath J. 2001;90(3):118-25. http://dx.doi.org/10.1054/ homp.1999.0476.

33. Benseñor IM, Atta JA, Martins MA. Semiologia clínica. São Paulo: Sarvier; 2002.

34. Schmidt P. A arte de interrogar. São Paulo: Editora Organon; 2004.

35. Farmacopéia brasileira. 5a ed. Brasília: Anvisa; 2010. Disponível em: http://www.anvisa.gov.br/hotsite/cd farmacopeia/pdf/volume1\%2020110216.pdf.

36. Stolberg M. Inventing the randomized double-blind trial: the Nuremberg salt test of 1835 . J R Soc Med. 2006;99(12):642-3. Available from: http://www.ncbi.nlm. nih.gov/pmc/articles/PMC1676327/.

37. Jansen JP, Ross A. Homeopathic pathogenetic trials and provings: the need for harmonized guidelines. Homeopathy. 2014;103(1):1-2. http://dx.doi.org/10.1016/j. homp.2013.10.005.

38. European Committee For Homeopathy. Provings Subcommittee. Homeopathic drug provings guidelines. Brussels; 2004. Available from: http:// www.homeopathyeurope.org/publications/guidelines/ homeopathic-provings/ECH_Proving_Guidelines_v1.pdf.

39. European Council for Classical Homeopathy. ECCH Provings Working Group. ECCH guidelines for homeopathic provings. 2nd ed. Kenninghall; 2009. Available from: http://www.homeopathyoz.org/downloads/ECCHProvingGuidelines2009.pdf.

40. Teut M, Hirschberg U, Luedtke R, Schnegg C, Dahler J, Albrecht H, et al. Protocol for a phase 1 homeopathic drug proving trial. Trials. 2010;11:80. doi: 10.1186/1745-6215$11-80$ 